


\section{NOTICE}

This report was prepared as an account of work sponsored by the linited states Government. Neither the United States nor the United States Department of Energy, nor any of their employees, nor any of their contractors, subcontractors, or their employees, makes any warranty, express or implied, or assumes any legal liability or responsibility for the accuracy, completeness or usefulness of any information, apparatus, product or process disclosed, or represents that its use would not infringe privately owned rights.

Printed in the United States of America

$$
\text { Available from: }
$$

National Technical Information Service

U.S. Department of Commerce

5285 Port Royal Road

Springfield, Virginia 22161

Price Printed Copy \$__ ; Microfiche $\$ 4.50$

\section{Pases}

$1-25$

25-50

$51-75$

$76-100$

$101-125$

$126-150$

$151-175$

$176-200$

201-225

$226-250$

$251-275$

$276-300$

301-325

$326-350$

$351-375$

$376-400$

401-425

426-450

$451-475$

476-500

500-525

526-550

551-575

567-600

NTIS

Selling Price

$\$ 7.00$

$\$ 8.50$

$\$ 10.00$

$\$ 11.50$

$\$ 13.00$

$\$ 14.50$

$\$ 16.00$

$\$ 17.50$

$\$ 19.00$

$\$ 20.50$

$\$ 22.00$

$\$ 23.50$

$\$ 25.00$

$\$ 26.50$

$\$ 28.00$

$\$ 29.50$

$\$ 31.00$

$\$ 32.50$

$\$ 34.00$

$\$ 35.50$

$\$ 37.00$

$\$ 38.50$

$\$ 40.00$

$\$ 41.50$
For documents over 600 pages, add $\$ 1.50$ for each additional 25-page increment. 
PPPL $=-2560$

DE89 004621

\title{
Local Carbon Diffusion Coefficient Measurement in the
}

\section{$S-1$ Spheromak}

K. M. Mawo: F. M. Levintun' D. D. Meverhofer! T. K. Chu. S. F. Paul. and M. Yamada Princeton University.

Plasma Phỵsics Laboratory,

Princeton, Vew Jersey 085.4

Inited States of America

\begin{abstract}
The local carbon diffusion coefficient was measured in the $S-1$ spheromak br detecting the radial spread of injected carbon impurity. The radial impurity density profile is determuned bv the balance of jonization and diffusion. Using measured local electron temperature $T_{c}$ and density $n_{e}$, the jonization rate is determined from which the particle diffusion roefficient is inferred. The results found! in this work are consistent with Bohm diffision. The absolute magnitude of $D_{i}$ was determined to be $(4 \sim 6) \times V_{\text {Dohm }}$.
\end{abstract}

\footnotetext{
Purdur Liniversity. West lafayette, Ii +79ut

'On assigument frum JAYCOOR. Turrance. C:A 945113

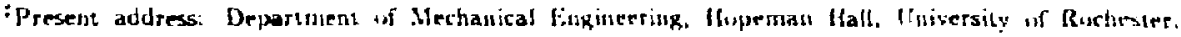
Huchester NY 14627
} 


\section{Intruduction}

The spheromak $I$, is a toroidal magnetic confinement plasma device which has received ronsiderable attention in recent years. Because the spheromak plasma generates most of its .jwn confining fields. there is no need for intrusive torcidal field coils that link the plasma. Thus, a simply rlused vessel geumetry is emploved which greally enhances the spheromak reactor potential. In addition, the spheromak plasma has polondal and toroidal fields which are of approximatelv equal magnit udes. This is a consequence if the force-free equilibrium andition $(\vec{j} \times \vec{B}=\Gamma p \sim 1)$ investigated by Rosenbluch and Bussaci 1 :

It has bren otsseried that spheromak plasmas may deviale from the force-free state. Ther mat then iend to relaz so that the force-free state is once agan acheved. as predicted b. Tixlor 21 . Cuncomitant with thes phenomenon of relaxation is the possibilit: of enhanced particle and energy transport. The purpose of this work is to directlv measure the l, cal particle transport coefficient, $D_{1}$, and compare this with classicallv predicted vadues.

Hany methods for such measurements have been considered previously. A review if sisme of these is given in Ref. 5 . Methods like $H_{a}$ monitoring and working gas putfing not only have the disadvantage of providing only global $\tau_{p}$ estimates, but have infierent difficulties associated with large neutral densities outside the $S \cdot 1$ separatrix and large transit times compared to plasma lifetimes, respectively. Sirnilar time scale problems exist with laser blowoff techniques. In situ impurity studies rely to a large degree on computer modeling of transport phenomenon and would again provide only global information by virtue of broad impurity profiles created by high transport rates in the $S$ - 1 device.

For this work we have chosen a scheme similas to that of Levinton and Meyerhofer/5: anrl have extended the method to higher temperature plasmas. Previous results in the I'rrin, S I, ( spheromak:6: have revealed that perpendicular particle transport occurs at a rate of 5 times Bohm over a limited parameter range. Here we have made measurements in a plasma with a larger range of magnetic field U.9 $2.5 \mathrm{kC}$; and electron temperature 


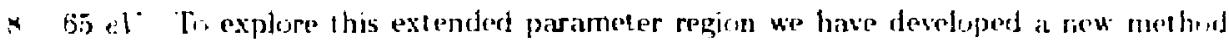
if steddy-state impuritv injection. The techniçue involves injecting impurities lorally in The plasma (near the magnetic axis) be means of a graphute epped prothe The radial diffusirn of C/I (spertrosecopic notation) is followed spertroscepically using a multicherd sustem which allows entire spatial emission profiles to be rerorded on a sungle discharge. The badance between diffusion of $C I /$ particles and irinization $t .,(" / I /$ determunes the widt h if the spatial emission profile about the injertion ponnt.

The diagncstic technique will be described in Section 2. In Sectun 3. the analitic methods used fior calculating $D$. from the emission profiles will be presented. Finallv the results and scaling of $D$. with plasma parameters will be discussed in Section 4.

\section{5 I Experimental Conditions and Diffusion Measurement Diagnostic}

The 5 I device and major components have been described previusslv $i .8$, as well as the method if programmed formation 99 . In the present experiment. discharges were produced to provide global stability to tilt and shift modes lol br a pair of passive conducting cones. Enhanced stability provided by these funnel (cine) stabilizers allows for transport studv which has not been previously possible on this machine. The $S$ - I device and spark probe diagnostic are shown sch naticallv in Fig. 1.

\subsection{Plasma Conditions}

Bv charging the programmed poloidal and coroidal field producing capacitor banks to * $\quad 1.1 \mathrm{k} \cdot \mathrm{l}^{*}$. spheromak plasmas were creaced with toroidal plasma currents from $80 k$.A to i N11 k.t. The peak magnetic field in the plasma ranged from $1.0-2.5 k G$. Hydrogen fill gas wits pulfed into the vessel several seconds before discharge initiation to a pressure of $\sim 5 m$ Torr. This uperation produced plasmas with electron densities of $\left(1.5-1 . \overline{5} \times 10^{i \cdot 4} \mathrm{~cm}\right.$ : and electson tomperat ures ranging from $8-6.5 \mathrm{el}$. The trpiral ulume-areraged beta. ' $J$ ived, 
is $2.875 \%$. These spheromak plasmas 1 poirally lasted from $11.511 .7 \mathrm{mss}$ The tume from $1-11 \mathrm{t}, \sim 270 \mu \mathrm{s}$ is the plasma breakdou'n and firmation phase. After formation. the spheromak equilibrium is seen tis approach a Taylor state 9 . Low current discharges rend

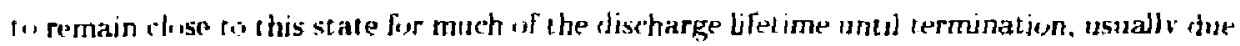
is an $n$ I mode. In hyher current discharges, hwwever, the lorridal current density and

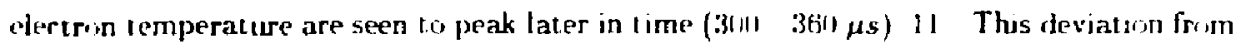
the Tavlor state is usually followed by a sudden relaxation of the plasma to an equitibrium which is unce agaln near the Tarlor state. This relaxation is chararterized br a noticeable Hattening if the tirmial current density and electron temperature profiles. It has been cunjectured II that at this time of retaxation, confinement is degraded. It will be shown later that cunlinement act ually begins to degrade well before the relaxation time and that 1 rinspurt rates are contunually increasing up to the relaxation time.

\subsection{Carbon Injection Diagnostic}

The $D$. measurement diagnostic has been ardopted and modified from that previously described 5 . We inject a small, localized source of carbon impurity directly into the main budv or the plasma. The injection point was in the injolane $(z=1)$ and at $R$ (major radius) pusitions of $R=33 \mathrm{~cm}$ and $12 \mathrm{~cm}$ (Fig. 2). The magnetic axis for these plasmas during the diffustun neasuring time ranged between 45 and $55 \mathrm{~cm}$. while the minor radius was $\sim 25 \mathrm{~cm}$. The injection probe consists of two graphite electrodes connected to a $15 k l^{\bullet}, 2 \mu F$ capacitor bank assembly (see Fig. 1) rarum sealed in a 3/8" (O.D.) stainless steel tube. Carbon mav be injected as a time drpendent source by discharging the capacitor bank $(\sim 2 \mu s$ quarter wale rise time) through the graphite electrodes. Carbon is also injected continuously by the interaction of the plasma with the probe tips. This allows a nearly steady-state injection during the discharge and provides an independent method of analysis. It also allows determunation of the diffusion constant in higher temperature $(\approx 10 \mathrm{el})$ plasmas where the pulse-injected sources quacklv $(<11 \mu s)$ disippeas bv ionization. 
Tho radial emission profiles for $C / /$ are recorded on a single shot using an chetical Multichannel Analver (ONIA) sustem $122^{*}$. The imaging optics consist if une $1-12$ " simple sonvex quart z lens, $1 / 2$. The lens is mounted bet ween the fiber fermile and the quariz window (swe Fig. 2) so that the image of the fibers is formssed at the midplane w the machine $(-1 \mathrm{~m}$ from the winduw) with a $15 \mathrm{~cm}$ radial spread centered at the spark probe. A 12 mom wide

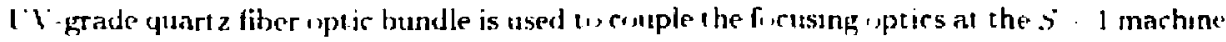

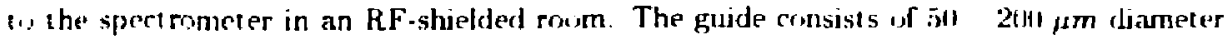
fused silica fibers individually clad in $111 \mu \mathrm{m}$ silionn. The $111 \mathrm{~m}$ hong gride is procected by a rirnagated plastir sheath and the ends are mounted in plastic ferrules in a coherent line Givide 1 ransmission is arceptable down $1,0 \sim 2513 \mathrm{~mm}$ at which the allematusn approaches I $d b / m$ and the transmission drops to $=1 \%$.

The spectrometer is an ISA-HR320 high throughput $11.32 \mathrm{~m}$ Czernv-Tumer f:4.8 instrument. Wich a $600 \mathrm{~g} / \mathrm{mm}$ holographic gratıng, a sesolution of $\sim 2$ A and a nominal range of $625 \mathrm{~A}$ can be achieved. This large range allows for the simultaneous detection of $C / /(4267 \mathrm{~A})$ and $C / / I(4647 \mathrm{~A})$. The instrumental resolution, however, is insufficient ir, measure Duppler shifts or broadening.

The detertis is a P:4RC 1254 silicon intensified target vidicon consisting of a $512 \times 512$ arrav of phutucathode plements with an active area of $12.5 \mathrm{~mm}$ bv $12.5 \mathrm{~mm}$ and a resolution if :-2 A channels. This ewo-dimensional detertor array is used tö record plasma emission as a functiun of wavelength and radial position. In addition to being placed in an RF-shielded $r(\%) \sim x m$ from the $S-1$ machine, the E.III sensitive electronirs are placed in a soft iron sleeve to reduce deflection. The detector is also equipped with a PARC 1211 high voltage pulse generator and a PARC 1216 detector controller to control gating and data transfet ti; the VAX / VMS computer svstem. The minimum gate time for the detector is 411 ns alt hough $520 \mu \mathrm{s}$ is tvpically required to collect sufficient light to resolve the line spectra abrite backgtrund. Since high time resolution is required for the carbon injertion experiment. 5 (1) $\mu$ g gate times were used thoughout. The readout ume for the detertior is $\sim$ illl ms 


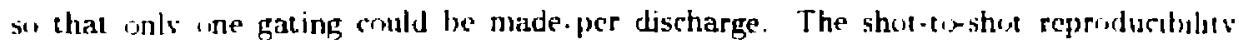

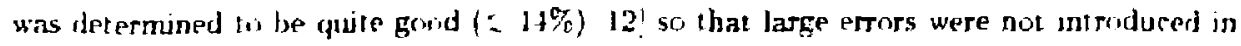
shot-bs-shol sranning.

Tw" Le(rov 8201 memorv modules are used in each garing. One module is filled $21 \mathrm{~s}$ before the discharge te record the background light. levels which are later subtracted from the plasma enission recorded during the shot in the wher mamurt mudule. An example spectral emission trace (with background subtracted) for one radial position of a trpical rarbun injectun discharge is shown in Fig. 3a.

A multipoint Thomson Srattering diagnostic 13.14 measures the locai salues of $T_{e}$ and $n_{\text {e }}$ at 5 to III spatial pusitions across the plasma radius, which are used to calculate the C $/ /$ Ionization rate. Iinization rates are taken from Bell et al. Liz. Loral magnetic field strengths in the kication of the injortion probe were measured bv a linear array of pickup fomps 16 enrased is stainless steel tubing and inserted into the spheromak midplane.

\section{Measurement Technicue and Analytic Methods}

\subsection{Measurement Technique and Assumptions}

Since the injected source is in the plasma midplane, the racial direction is the $\Gamma u d j$ rection ( $w$ is the joloidal flux function). Hence, the radial evo'ution of the carbon impurity is determined by perpendicular transport alone. The parallel diffusion coeffirient, $D_{;}$, cannot be inferred from this measurement as has been done on a similar experiment on Proto $5-1 / C \quad 5$ since the focusing optics cannot be moved to other toroidal locations around the $S$ - I machine.

As mentirned earliet. two myection schemes have been utilized, the pulsed injection and the steadr-state injection methords. The equivatence of these in determining $D$. will be denwnstraled later In realily. the steadv-slate source is alwavs active even during pulsed injertu, nstex the probe injects continucuslv through plasma particle hombardment 


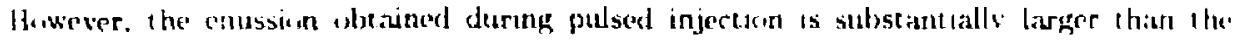
steady-siate emission. so the 1 wo sources are easilv distinguished In the pulsed injertion method. approximatelv $5-6 k . t$ of current flows bet ween the graphute probe tips producing a lurad dipule field of nearly $20 k G$. This represents a large local perturbatou during the pulse. Hence. the details of the pulsed injection will now be modeled. Ondv after the probe current decas's to zeso will ihis data be analvsed.

In buth injection methods. the presense of the probe in the plasma and the increased ımpurıx densitx due to injecturn catse insigniticant perturbations t, the plasma. Figure 3a shuss the carbon emission with the injection probe in the machine and Fig. 3h is a simular discharge with the probe out of the machine. The local injected carbon densits is substantially greater than the background levels, although the glohal carbon concentration did not increase signiticantly. There was no measurable reduction in the local electron temperaiwe br the impurity injertion. This is consistent with the large values of parallel electron thermal conduction experted 6 i. In addition, similar diffusion coefficients were obtained whet using borth the steadv-state and pulsed injection techniques, the latter method licallv introiductes altmist an urder is magnitude more carbon injtially.

It is evident, from a consideration of the ion thermal speed $v_{t h}=\frac{d i T_{1}}{m_{1}}-3.3 x$ $111^{4} \mathrm{~m} / \mathrm{s}$ for carbin at $T_{t}=T_{e}=70$ el (the highest electron temperature obserted in this experiment) that it would take a time longer than the discharge lifetime for the injerted carbon 1, fll an entire flux surface. In audition, perpendicular diffusion and jonization ensiure that the only observable impurity concentration remains in the virinity of the probe. Therefore, the impurity confinement is determined by the local magnetic field near the jnjection point rather than the entire flux surface. Furthermore, it is assunied that the ibserved transport may be described by a single quantity. $D_{-}$, while looking in the plane of the probe (i.e.. $==(1)$ ).

The gradient scale lengths and time scales for change in plasma paramelers in the seed 
i I plasma are long compared 81, these of the imjected carbon. Therefore, it is assuned that the diffusion roefficient is constant during the short observation ume $(5 \sim 11)$, ss $)$ in the steadv-state method and during the temporal evolution directv following the pulset injectusn. The justification of the latter condition lies in the obsertation of approximatelv wnstant (in time) electron temperatures in $S$ - I plasmas for low voltage discharges $1:$ II $\mathrm{h} \mathrm{l}^{\circ}$. the only condition where the pulsed lechnique mav be emploced.

Experimentally it has been determined that all the unjected carluon is mitially in the (') charge slate. This has been verified bv discharging the probe in vacuum. neutral fill

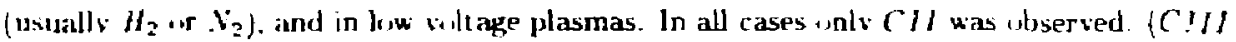
was . Hserved in the low wiltage plasma case but not above the normal background.) Hence, It is assumed that the sulurce term is that of C/I alone. This assertion is of substantial consequence since 11 remuses the need to model neutral transport.

It is also assimmed that in the vicinity of the jnjertion probe the electron temperat ure and density are spatially ronstant. The ionization rates then become ronstants in the rate equations and the emission perfiles may be regarded as relatıe impurity densiev profiles. The constant $n_{e}$ assiumption is quite well justified based on laser Thumson Scattering. In the case of $T_{\text {e }}$ some profile peaking does appear in the higher viltage discharges. However.

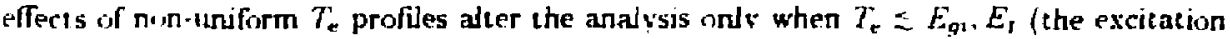
and innzation energies, respertively). These ase 211 and $24.4 \mathrm{el}^{-}$for $(C / I$ at $4267 \mathrm{~A}$ so there will , ntv he important profile effects when $T_{\mathrm{e}}$ is $\mathrm{low}\left(\approx 21 \mathrm{el}^{\circ}\right)$. The electron temperature trpically takes on these values in the case of low soltage discharges where the profiles tend ti, be flat anrwav. Hence, $T_{e}$ profile effects are experted to be minor.

Finally; for the steadv-state method it will be assumed that the charge states $C / I$ and $C / / J$ have reached equilibrium determined $b$ electron impact innization and cross field transpirt. Because the obsermation times are long affes the plasma breakdown is

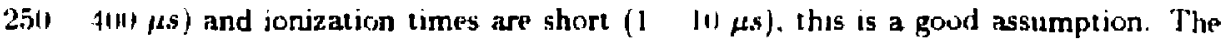


efferts if recombination are assumed to be negligible on the time scales of the discharge. Excitation is assumed to orcur bet ween the ground state and the upper level of the transition being studied. This $\mathrm{j}$ a a good assumption for the relatively low electron densities in this experiment since collision times are much longer than the decay times of must excited states (except for metastable states). The above assumptions also applv to the pulsed injection method. exrept that charge state equilibrium is not achioved until well after the probe firing time. The temporal evolution of the charge state densities must be followed in this case.

\section{2. -Inalutic Solutions}

The analvsis of the emission profile data proceeds by solving the impurity continuity equation.

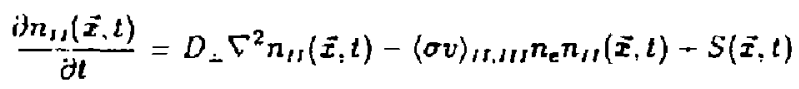

Hers $n_{n}(\hat{x} . t)$ is the CII density, $\langle\sigma t\rangle_{n, 1,}$ is the electron impact ionization rate coefficient from $C I I$ to $C I I I$, and $S(\ddot{x}, t)$ is the $C I J$ source term. This model ignores electron density gradients and assumes that the injected ion density gradjents drive the diffusion. In particular, it is collisions between carbion ions and protons which are of interest. It is this fact that allows the transport term to be expressed as depending on the individual charge state density only. The source term $S(\vec{x}, t)$ is found by discharging the carbon probe in $H_{2}$ neutral fill gas and in low $T_{e}$ plasma discharges. A sample source emission profile for $C I I$ at $4267 \mathrm{~A}$ is shown in Fig. $A$ with a superimposed gaussian curve

$$
S(\vec{x}, t)=C \exp \left(-r^{2} j r_{0}^{2}\right)
$$

where $r_{o}=0.83 \mathrm{~cm}$. The parameter $r_{o}$ in $\mathrm{Eq} .(2)$ was determined from the average of mant such discharges and will be used in the CII source expression throughout. Equation (1) can be simplified to one dimension

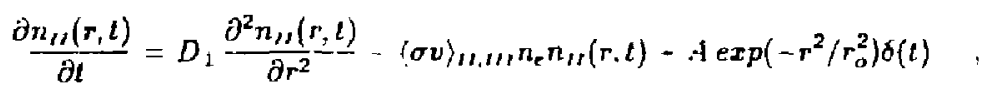


and may be solved by the method of Fourier transforms to yield

$$
n_{1 r}(r, t)=\frac{A r_{0} e^{-D_{\perp} \alpha^{2} t}}{\sqrt{r_{a}^{2}+4 D_{\perp} t}} \exp \left(-\frac{r^{2}}{r_{o}^{2}-4 D_{\perp} t}\right),
$$

where $\alpha^{2}=\frac{(\sigma v\rangle_{1, r m} n_{e}}{D_{\perp}}$ so that $\alpha^{2} D_{\perp}=\frac{1}{\tau_{i o n}}$, the ionization rate for CII. The $t$ in Eq. (4) refers to the time after firing the probe (i.e., $t=0$ ), the time when the spark current turns off).

To quantify emission profiles obtained during plasma discharges when the probe capacitır bank had not been fired, we now imagine a time-independent $C ! /$ continuiti equation of the form

$$
0=D_{-} \frac{\partial^{2} n_{I}(r)}{\partial r^{2}}-\langle\sigma v\rangle_{H, H} n_{e} n_{H}(r)+A \exp \left(-r^{2} / r_{o}^{2}\right)
$$

Equation (5) is assumed to be a steady-state equation only during the gating time of the instrument $(5-10 \mu s)$. All the coefficients, including the source term, are assumed to be constant during this short time, a valid approximation in the present experiment. To follow the time history of the discharge, we gate at varied times on a shot-by-shot basis. The coefficients may vary on times long with respect to the gating time. This is accounted for by recording $T_{e}$ and $n_{e}$ at times in the discharge corresponding to detector gating times. As before, we employ the method of Fourier transforms to Eq. (5). The steady-state solution for the $n_{I I}(r)$ protile is

$$
R_{r}(r)=\frac{A r_{0} \sqrt{\pi}}{4 \alpha D_{\perp}} e^{\alpha^{2} r_{0}^{2} / 4}\left\{e^{-\alpha r}\left[1+\operatorname{er} f\left(\frac{r}{r_{0}}-\frac{\alpha r_{0}}{2}\right)\right]+e^{\alpha r}\left[1-e r f\left(\frac{r}{r_{0}}+\frac{\alpha r_{0}}{2}\right)\right]\right\},
$$

where $\operatorname{erf}(x)$ is the error function[17]. In the limit $a r_{0} \ll 1$, the solution becomes

$$
n_{I S}(r) \sim \frac{A r_{o} \sqrt{\pi}}{2 \alpha D_{1}} e^{-\alpha|r|}
$$

which is exactly the solution one would obtain by using a spatial delta function source term in Eq. (5). From this limiting form it can easily be shown that

$$
D_{\perp}=\langle\sigma v\rangle_{H, H S} n_{e}\left(\frac{r_{l / 2}}{\ln 2}\right)^{2}=\frac{r_{1 / 2}^{2}}{(\mathrm{LI} 2)^{2} r_{i o n}} \quad,
$$


where $r_{1 / 2}$ is the half-width of the protile. This is exactly the result that would be expected for ionization balanced diffusion at steady-state. Equations $(\bar{i})$ and $(8)$ have a convenient and simple form. yet, they cannot be used in prartice. The scurre width, $r_{o}$, is not negligib]e un the length scale of $r_{1 / 2}$ and, therefore, cannot be ignored. Equation (6) must be used.

\subsection{Eialuating D. from Experimental Enission Profiles}

From the derivations of the previous Section, we can now evaluate $D$, from the $C I I$ measured emission profiles. Two methods were developed so that independent measures of the transport quantity may be obtained as wel as ensuring the applicability of at least one method over the entire range of plasma parameters. We may proceed from the formalism of Eq. (-7) by analyzing data like that presented in Fig. 5. Here the peak of the C II emission profile is fillowed in time from the probe firing time $(2511 \mu s)$. The open circles represent the emission peaks abserved after the probe was fired while the closed circles are the profile peaks for the non-firing, steady-state case. (The steady-state case represents a background in this method of analysis.) The solid line is a close fit estirrate from Eq. (4) with $r=0, n_{e}$, $T_{E}$ (and hence $(\sigma v\rangle_{t, I J I}$ ) fixed. $D_{2}$ is varied until a good fit is obtained. For this particular case $D_{1}=(1.0 \pm 11 . \overline{\mathrm{t}}) \times 10^{\overline{5}} \mathrm{~cm}^{2} / \mathrm{s}$. The large error is the difficulty with this approach. Besides shot-to-shot variation in the peak heights and the insensitivity of the time history to the $D_{-}$value, the ionization times are short compared to the time between gatings in all but the lowest $T_{e}$ discharges $(8-12 \mathrm{eV})$. For the data in Fig. $5, T_{c} \sim 9 \mathrm{el}$. When the electron temperature is increased, the jonjzation times become short surh that a difference in the emission profile above background is not noticed after the first gating time. Therefore, this method cannot be used for much of the data. For this particular case $D_{1}$, estimated from. the steady-state ar Jysis (Eq (6)!, was determined $t a$ be $(1.6 \pm 0.4) \times 10^{5} \mathrm{~cm}^{2} / \mathrm{s}$, establishing qualitative agreement between the two independent methods.

Since the time-dependent technique has been shown to be viable in earlier work 5 ,, it 
is instructive to further expound the connection to the steadv-state method which will be used throughout this work. In analyzing the time-dependent emission profile it is necessary to include the ubiquitous steady-state emission profile. Since these equations are linearly independent solutions of the same differential equation, their sum is alsis a solution. We mav. then. add the two solutions $\mathrm{Eq}$ (4) and (6) to simulate the time-dependent experimental profile data. The one-dimensional profile mav be completely specified by a single paramerer. $r_{1 / 2}$ (the hall-width at hall-height). In Fig. 6. $r_{1 / 2}$ for $C / /$ is plotted vs time after firing the spark probe $(335 \mu s)$. The open circles represent the experimental data with the error bass indicating the scatter in the value of $r_{1 / 2}$. The dashed curve through the closed circles represents the resulting $r_{1 / 2}$ values sbtained in the simulation. The analvitic trace is in grond assreement with the data. Here a value of $D_{-}-(1.55=0.54) \times 11^{5} \mathrm{~cm}^{2}$;s was used in the simulation as determined by the method of peak heights described above. The solid line at $r_{1 / 2}=1.3 \mathrm{~cm}$ is that value for the steady-state emission profiles ubthained under similar conditions. A steady-state $D_{1}$ value of $(1.9 \pm 0.6) \times 10^{3} \mathrm{~cm}^{2} / \mathrm{s}$ was determined from this data. Within the error bars of the measurement, the time dependent and steadystate evaluation of $D_{\perp}$ are identical. Since the steady-state method may be used over the entire range of plasma $i$ arameters in this experiment, it will be the only method considered hereafter.

Before leaving the time-dependent emission behaviour completely, some physical insight into the ionization balanced diffusion problem may be gained by examining Fig. 6 in more detail. Just after firing the spark probe at $335 \mu \mathrm{s}$, the emission profile is quite narrow. Since the carbon will have had little time to diffuse from the source, the emission profile is nut verv different from that of the source term. As time progresses, the spark injected carbon profile broadens under the action of diffusion. This happens quite rapidly because of the short gradient scale lengths for diffusion at this time. The half-width becomes larger than that of steady-state, even though the ionizatiun rate is constant. Note that if the jonization rate were zero, the $r_{1 / 2}$ trace would diverge like $v i t$ as can be seen from Eq. (f) 
This behaviour is closely followed in Fig. 6 from 335 to $345 \mu \mathrm{s}$. After 345 us irmizatun becomes more comparable as the gradient scale length is increasing (the $C / /$ density profile is flattening). Finally, the profile decays to the equilibrium solution where diffusion is completelv balanced bv ionization (at $\sim 365 \mu s$ in Fig. 6). This broadening and peaking behaviuur is only observed in low $T_{e}$ discharges. In high $T_{e}$ discharges the jonization time firr $(I / /$ becomes ton, short to notice any profile broadening above the steadrstate value of $r_{1,2}$. The $r_{1,2}$ vs. time trace in this case monotonicallv approaches the steadv-state solution

Returning to the more practical endeavor of finding equilibrium solutions, we note that the solution to Eq. (6) may be written in the form

$$
\text { i) } \frac{n_{o}}{2}-n_{o} f\left(D_{\perp}, r_{1 / 2}\right) \text {, }
$$

where $n_{a}$ is the peak density and $f$ is the functional form of the density profile viewed as a function of $D_{-}$and $r_{1 / 2}$. The procedure for determining $D_{\perp}$ is to iterate on $D_{-}$at a fixed $r_{1 / 2}$ (determined from the experiment) to find the zero of Eq. (9) using the Newton-Raphson method. This method is guaranteed since the right hand side of Eq. 9 is monotonic in $D$. for a fixed $r_{1 / 2}$, exhibiting only one zero. Convergence to 1 part in $10^{6}$ is usually obtained in 5 - III iterations.

Effects which may lead to distortion of the envission profiles from the analytically expected density profiles, like the inclusion of bulk plasma motion in the rate equation and atumic physics issues of recombination and non-uniform plasma parameter profiles. Were investigated by numerical solution to the coupled species rate equations 18 ! For the conditions of the experiment and for reasonable estimates for neutral densities, these effects were . seen to make negligible contribution to the emissivity profiles. 


\subsection{Error Analisis}

Sources of ersor in this analysis stem from 1) uncertainties in the plasma parameters $n_{r}$ and $T_{r}$ which affect $D_{-}$through the ionization rates: 2) uncertainties in electron impact ionjzation cross sections, $\sigma_{e i}$, given in the literaturei 15.19 ; and 3 ) uncertainties in the measured walues $r_{0}$ and $r_{1 / 2}$ which affect the interpretation of the emission profile and. henre. $D$. The standard error in the recommended cross-section data is clamed to be

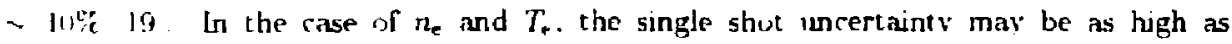
$310^{6 \%}$. greater. However. since we have manv shots at similar plasma conditions, we mav rmplw shot averaging of individual Thomson scattering wavelength channels to reduce the uncertainties in $n_{e}$ and $T_{e}$ to $\sim 10 \%$ in most cases. Thus is a significant improvement wier the method of arithmetic averaging of the $n_{e}$ and $T_{r}$ values attained on each shot, uthich does not improve counting statistics and is biased toward higher $T_{e}$ values by Poisson statistics 2 (t)

In addition to the relative uncertainty in $n_{e}$, there is an absolute error assoriated with calibration assumptions and uncertainties. This is estimated to be $\sim 20 \%$.

While errors in $\sigma_{e n}$ and $n_{e}$ produce relatively mild uncertainty in $D_{\perp}$, the uncertainty produced bv errors in $T_{e}$ is usually more pronounced. This can be easily understood by noting the strong dependence of $\langle\sigma v\rangle$ on $T_{e}$, especially when $T_{e} \Xi E_{t}$. For example as $T_{e}$

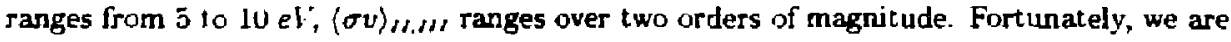
seldom un this very low temperature range and the uncertainty in $T_{e}$ is typically $\leq 10 \%$, thus keeping the resultant $D$; uncertainties to acceptable levels.

There is also an uncertainty in the source width, $r_{0}$, which leads to error in $D_{\perp}$. The pussible range of $r_{0}$ values can be estimated from source profiles like that of Fig. 4. From this we find $r_{0}=(0.83 \pm 0.1) \mathrm{cm}$.

Similarjy. there are errors in experimentally determining the $r_{1 / 2}$ values. The source of these uncertainties is shot-to-shot reproducibility and photoelectron counting statistics. 'The 
Table 1: Average Parameters fi, an $8 \mathrm{kl}$ Discharge at $335 \% \mathrm{~s}$

\begin{tabular}{|c|c|c|c|}
\hline Parameter & Vialue & L'nits & 7 crror in $D$ \\
\hline$T_{e}$ & $10.1)=0.15$ & el & 12.3 \\
\hline$n_{e}$ (relative) & $5.11 \pm(1) .1$ & $11^{13} \mathrm{~cm}^{3}$ & 5.7 \\
\hline$n_{e}$ (alisolute) & $7.11=1.4$ & $10^{13} \mathrm{~cm}^{3}$ & 19.4 \\
\hline$r_{n}$ & $11.83 \pm 0.1$ & $\mathrm{~cm}$ & 23.4 \\
\hline$r_{1 / 2}$ & $1.23=0 . .016$ & $\mathrm{~cm}$ & 19.6 \\
\hline$\langle\sigma 2\rangle_{1 / H}$ & $11.2=01.112$ & $\mathrm{I} 1^{-\mathrm{H}} \mathrm{cm}^{3} / \mathrm{s}$ & 11.11 \\
\hline
\end{tabular}

latter is relatively unimportant. in this context. Since the count rates are tupically severad hundred to several thousand counts, the error encountered from photuelect sein rounting is only a few percent. In addition. shut-to-shot deviation typically int ruduces ancther $5 \sim 110 \%$ uncertainty in $D_{!}$.

Since all of these sources of relative error may be regarded as independent, thev will cumbine in quadrature (i.e., the relative variances will add). The propagation and acrumulation of error is best illustrated by an example. The parameters of concern for the average $\mathrm{k} k \mathrm{I}^{-}$discharge at $3335 \mu \mathrm{s}$ are given in Table 1 along with their uncertainties and percentage errors they produce in $D_{\perp}$. These were estimaled by recalculating $D_{!}$using the value $\boldsymbol{x}=\boldsymbol{\sigma}$ in place of $I$ where $x=T_{e}, n_{e}, r_{c}, r_{: / 2}$, $(r)$ ). The effect of each value was rthorked indepen dently. In quadrature, these errors accumulate to a $40 \%$ uncertaintv in $D$. From this we mav quote $D_{\perp}=(1.24 \pm 0.5) \times 10^{5} \mathrm{~cm}^{2} / \mathrm{s}$. 


\section{Results and Scaling}

\subsection{The Functional Form of $D$.}

The functional dependencies of $B$ and $T_{e}$ in the diffusion coefficient are revealed in an examınation if the profiles shown in Fig. 7 . The electron temperature for profile ia and profile its are 38 and $63 \mathrm{el}$. respectivelv, while the magnetic field strength and electron density are nearly the same. In addition. the ionization times are approximatelv equal being $11.89 \mu s$ and $11.9 \mu s$, respertively. (This is due to the compensating effects of small densiry (hauge and small rate coefficient change for the large temperature difference.) Since the width of profile $i b$ is larger than that in profile $i a$, it has the larger value of $D_{-}=$ $(2.1)^{2}=(1.42) \times 11^{6} \mathrm{~cm}^{2} / \mathrm{s}$ while that of profile $7 \mathrm{a}$ is only $(5.0 \pm 1.9) \times 10^{5} \mathrm{~cm}^{2} / \mathrm{s}$. Thus, there is a strong $T_{e}$ dependence.

We mav proceed in a similar manner for profiles $7 \mathrm{c}$ and $d$ which have different magnetic field strenghts $(921)$ and $1450 G$, respectively), but nearly the same $T_{e}$ and $n_{E}$. Again. the ionization times are simular being $2.7 \mu s$ for $7 \mathrm{c}$ and $2.1 \mu \mathrm{s}$ for $\mathrm{id}$. Now, however, the profile extent has decreased in going from $7 \mathrm{c}-\mathrm{d}$ and the diffusion constants are $(3.78=1.27) \times$ $11^{5} \mathrm{~cm}^{2} / \mathrm{s}$ and $(1.86 \div 0.8) \times 10^{5} \mathrm{~cm}^{2} / \mathrm{s}$, respectively. Hence, there is an inverse dependence on $B$

We now examine the electron density dependence. In the operation of the $J$ - 1 machine, it is difficult to vary the electron density independently of other parameters. In particular. at constant ill pressure there tends to be an inverse dependence of $T_{\varepsilon}$ on $n_{\varepsilon}$. As $n_{e}$ increases the electron temperature decreases as can be seen in Fig. 8. Consequently, the $\pi_{e}$ dependence in $D$. mav be examned by considering a small window in parameter space in which $T_{\text {e }}$ and $B$ do not vary substantially. Figure 9 is an example of such a window. In this case. $45<T_{\varepsilon}<65 \mathrm{el}$ and $2100<B<2500 \mathrm{G}$ while $n_{\mathrm{r}}$ varies from $4.5-7.5 \times 10^{13} \mathrm{~cm}^{-3}$. In this range, $D_{-}$is inclependent of $\pi_{e}$. Although $T_{e}$ and $B$ do vary in this window, the ratio $\frac{T_{r}}{B}$ varies only by $\sim 21 \% \%$ where the range of $n_{e}$ is $\sim 67 \%$ 
The restal of all the above-mentioned functional dependence analvses results in a sraling relation.

$$
D_{.}=f\left(T_{e} B\right) \times \frac{T_{e}^{a}}{B^{b}}
$$

where the exponents $a, b$ and a constant mutiplies are to be determined. To this end, a multiple linear regression analvsis has been performed on $D$. with $T_{f}$ and $B$ as independent variables. In the regression. $T_{e}$ has the range $8 . \bar{i}-63.6 \mathrm{el}$ and $B$ varies from $\left.9211-2441\right)(;$. This results in a scaling

$$
D_{-}=6.509 \times 11^{6} \frac{T_{s}^{1.0750 .25}(\mathrm{e} /)}{B^{0.800 \pm 0.4}(G)} \mathrm{cm}^{2} / \mathrm{s}
$$

Here we have considesed data from $t \leq 3 \pi 0 \mu \mathrm{s}$ and from the probe position $r=42 \mathrm{~cm}$. Data from the edge $(r=33 \mathrm{~cm})$ will be discussed in sertion 4.3 . Hence, the scaling presented in Eq. (11) is intended to represent the spheromak central confinement characteristics at t.imes when the plasma is stable to gross MHD modes $(n=11,1)$. The scaling behaviour is indicated in Fig. 10 where $D_{\perp}$ is plotted against the regression on $D_{亡}$. Eq. (11).

These functional trends are apparent in the emission profile widths. In Fig. 11 the half-width $r_{1 / 2}$, minus the source width, $r_{v}$, is plotted against. $T_{e}$ for constant $B \sim 2400 G$ and $n_{r} \sim 7 \times 10^{13} \mathrm{~cm}^{-3}$. The solid line is $r_{1 / 2}-r_{0}$ ralculated from Eq. (6) assuming the $D_{\text {. }}$ scaling of Eq. (11). On the left side of the minimum $\left(T_{t} \leq 40 \mathrm{eV}\right)$ the behaviour is dominated by ionization since the rate coefficient increases an order of magnitude between $11+4 l l 1^{\circ}$ and the profile narrows. In the region bevond $40 \mathrm{eV}$, the rate coefficient becomes nearly constant and the curve turns upward, increasing with $T_{e}$. Assuming $\langle\sigma v\rangle_{\|, \Omega}$, remains constant. this relation would eventually approach $\sqrt{T_{e}}$.

Some sample values of $D_{-}, D_{\perp} / D_{B o h m}$, and $D_{\leq} / D_{L_{e t}}$ are listed in Table 2 along with relevant plasma parameters where

$$
D_{B \circ h m}=\frac{10^{8}}{16} \frac{T_{e}\left(e V^{\circ}\right)}{B(G)} \mathrm{cm}^{2} / \mathrm{s}
$$


Table 2: Sone values for plasma parameters. $D_{\ldots}$, and ratios for an average shol at iach condituon

\begin{tabular}{|c|c|c|c|c|c|c|c|}
\hline livunk & $n_{e}\left(10^{43} \mathrm{~cm}^{-3}\right)$ & $T_{*}(\mathrm{e})$ & $B(G)$ & $\ln 1$ & $D_{-}\left(\mathrm{m}^{2}\right)$ & $\frac{D}{D_{B \text { ahm }}}$ & $\frac{D}{D}$ \\
\hline 8 & 10. 4 & $9 . \bar{T}$ & 1060 & 10.3 & $2.7 \times 10^{5}$ & 4.6 & 1.2 \\
\hline 10 & 9.0 & 15.6 & 1420 & 11.1 & $3.5 \times 10^{5}$ & 5.1 & 4.0 \\
\hline 12 & 3.1 & 31.0 & 1860 & 12.2 & $5.9 \times 10^{5}$ & 5.6 & 17.9 \\
\hline it & 6.6 & 47.5 & 2460 & 12.9 & $7.4 \times 10^{5}$ & 6.1 & 51.7 \\
\hline
\end{tabular}

and

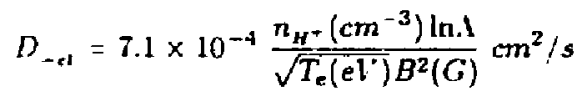

For Carlusn-Hvdrogen collisions assuming $T_{e}=T_{t}$.

The results $D_{+}, 5.25 \times D_{B o h m}$ and $D_{l_{e t}}$ are plotted in Fig. 12. In all cases, except those at resv liow $T_{e}, D_{-}$is clearly much greater than classical. The tendencv for non-classical behaviour persists throughout parameter space and the disparity from $D_{L_{\text {el }}}$ increases with $T_{\mathrm{r}}$. At the same time, the relation to $D_{B \mathrm{ohm}}$ holds quite well through the entire range of parameter space.

\section{2. $T_{r} \cdot T_{H} \ldots T_{c u l}$ Connection}

In the discussion of the previous Section, it has been assumed that $T_{1}=T_{e}$ in the evaluation of diffusion constant scaling. In reality, the temperature that should appear in $D_{-r l}$ is $T_{H^{+}}$since the classical transport is driven by $\mathrm{ClI}-H^{+}$collisions. To estimate the relation between $T_{e}$ and $T_{1}$, we determine the mean rate of collisional energy transfer between the species. This can be quantified by considering the equilibration time, $\tau_{a / b}^{e},{ }^{\prime} 21^{\circ}$. in cgs units

$$
\frac{1}{\tau_{a / b}^{e}}=1.75 \times 10^{-19} \frac{Z_{a}^{2} Z_{b}^{2} n_{b}\left(\mathrm{~cm}^{-3}\right) \ln \Lambda \sqrt{m_{a}(g) m_{b}(g)}}{\left[m_{b}(g) T_{a}(e V)+m_{a}(g) T_{b}(e l)\right]^{3 / 2}}, \quad s^{-1} .
$$


In low temperature $S-1$ plasmas $\left(T_{+}=111 \mathrm{el}, n_{+}=11 \times 11^{14} \mathrm{~cm}^{3}\right)$ we find that $T_{H^{-}}^{2}=8.3 \mu \mathrm{s}$ and $\tau_{C H / H^{*}}^{e}=2.3 \mu \mathrm{s}$ where we have taken $\ln .1 \sim 12$. At these low temperaltures it is reasonable to assume temperacure equilibration among the species.

At higher temperatures $\left(T_{\epsilon}=50\right.$ pl: $\left.n_{r}=i .0 \times 10^{13} \mathrm{~cm}-3\right)$ we calculate $\tau_{H}^{e} \cdot c=$ $133.11 \mu *$ and $\tau_{r}^{2} \ldots 14 .=38.2 \mu$ where again $\ln .1 \sim 12$. These long equilibration tumes should not be disconrerting, however. It should be noticed that $\tau_{a, b}^{e}$ is not a constant. As. 7. progresses from low to higher values, $\tau_{a / b}^{e}$ progresses from verv short to moderatels long tımes as $T^{3,2}$. Hence, the ions are able to keep up quite well initralls. It is onls when $T_{e}$ is verv large that classical energy exchange among species is signuficantly reduced. The restdit is that at these morlerate electron temperatures, $T_{1}$ is not expected to be significantly different from $T_{e}$. In addition, there exist anomalous (non-classical) heating mechanisms that produce higher ion temperatures than can be expected classicall. in addition. the error interduced in making thr approximation $T_{2}=T_{e}$ is reduced bv the $\sqrt{T}$ dependence in $D_{i, 1}$

\subsection{Time-Resolved Particle Transport and the Relaxation Phenomenon}

It has been illustrated 11 that in the $S-1$ spheromak a step-wse relaxation in $T_{e}$ and $j$ profiles occurs reproducibly in high temperature discharges similar to that first reported on CTCC - 122 ?. It has also been suggestedil 1 ? that. concomitant with the relaxation, there is a degradation in confinement. In this Section it will be shown that. although this may be true regarding energy confinement. it is most likelv not the case when considering particle confinement. The observation on $S-1$ is that particle transport is continuously increasing before the relaxation event and toes not show a marked increase during the event.

The relaxation scenario as posed in Ref. 11 i is as follows. In a high voltage (thus high $T_{\varepsilon}$ and $B$ ) discharge, transport alluws temperature gradients to build in the plasma center. causing the decay time of poloidal Sux (due to central toroidal currents) to be larger than 


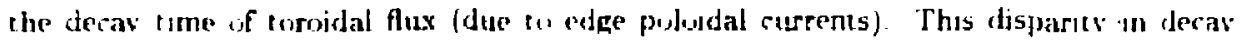
rales firres the spheromak plasma away from the lavlor state since the minimum energy sfate requires equal decay rates (i.e., self-similar deray). Thus. the implication is that the difference in checav rates is cauted by a resistivity profile The disparity in decav rates produres a p+lididad Hux rich plasma which moves awav from the Tavkor state and leads t.. studden relaxal uti. This roproducibly ucrurs in the 5 l plasma 360 3iti $\mu$ s after discharge formal ion.

Hart ef al. 23 . have investigated deviations from the Tarlor state br empluving the equilibrium condition

$$
\frac{j_{11}}{B}=I_{p}^{\prime}(\psi)+\mu_{0} \frac{p^{\prime}(\psi) I_{p}(\psi)}{B^{2}}
$$

Here. we have used the polojdal current instead of the traditional stream function. The prime denotes differentiation with respect to $\psi$. The Tavlor state of minmum energy requires that $j_{1} / B$ be a spatial constant (i.e.. $\mu=\mu_{0} \frac{J}{B}=$ const.). Thus, for this idealized state $I_{p}\left(w^{\prime}\right)$ must be a linear function of $v^{\prime}$ and $p^{\prime}=0$ everywhere. It has been shown I6 that thus is the case for previous $s$ - 1 low temperature plasmas where the only signufirant pressure gradient is at the edge. In the present experiment, the plasma is in the Tavior state at $\sim 310 \mu s$ after which pressure gradients are found in the bulk plasma. as can be seen in Fig. $13 k$ where $\kappa=\frac{1}{p} \frac{\partial p}{\partial}$. Figures $13 a, b$ show the measured $D_{1}$ vs. time for 10 and $1+k 1^{\circ}$ series of discharges, respectively. The circles represent outside data $(r=33 \mathrm{~cm})$ and the $I^{\prime}$ 's represent inside data $(r=42 \mathrm{~cm})$. The heavy dark lines are drawn to aid the eve in following the temporal trends. All the data (save one outside point in the $V=10 \mathrm{kF}$ case) fall within these two guide lines.

There are four topics of interest in Fig.13. Firstly, the temporal hehaviour of $D$. follows that if $k$ quite closely in the time interval 300 - $400 \% \mu s$. This indicates the influence of pressuse gradients causing deviations from the Taylor state and enhancing particle transport. Secondly, the eflect of pressure gradients is olserved in both the low $\left(l^{*}=111 \mathrm{kl}\right)$ and the 
high $\left(I^{\circ}=14 k l^{\circ}\right)$ curtent discharges. In both cases pressure gradients exist in the plasma while $I_{p}^{\prime}(u)$ deviations from linearity only exist in the latter case. As well, relaxation events only exist in the latter case. Thirdly, the inside $(r=42 \mathrm{~cm})$ and outside $(r=33 \mathrm{~cm})$ dat a agree qualitatively (showing the same temporal trend), indicating that the transport mechanism is not localized. Occasionally, there exists a larger diffusion constant for the - ist side data. It is conjectured that higher fluctuation levels in the plasma periphery, existIng throughout much of the discharge, may lead to enhanced diffusion by mixing parallel and perpendicular particle transport. This is also a possible explanation for the large diffusun rates early in the discharge during a period of violent magnetic activity following furmation. Fourthly, there is no sudden increase in the particle transport rate near the relaxation time $(\sim 37 / \mu \mathrm{s})$ in the $1.4 \mathrm{k} \cdot \mathrm{I}^{\circ}$ case. Rather, the particle transport rate builds as the pressure gradient increases in the plasma $(300-370 \mu s)$. The relaxation phenomenon sudderlv flattens the $T$ profile. This is indicated by a lower $\kappa$ value after $370 \mu s$ as shown In Fig. 13r. The particle transport rate then decreases following the drop in $\nabla p$ rather than showing a sudden increase as would be expected in a step-wise particle loss occurring at the relaxation time.

Dne possible physical picture is that the relaxation, happening on a short reconnection time scale, allows for a large amount of electron thermal conduction energy loss from the plasma center to the periphery which can occur on open field lines during the reconnection. Thus, the $T_{e}$ profile may quickly flatten. However, the transport of massive ions, occurring .un the much longer sound time, cannot occur to substantial proportions in the reconnection time period.

The preceding scenario could be qualitatively verified by some simple arguments. The . reconnection time may be estimated $[24]$ as

$$
T_{x} \sim \tau_{R}^{3 / 5} \tau_{d}^{2 / 5}
$$

where $\tau_{R}=\mu_{D} L^{2} / \eta$ is the resistive decay time and $r_{A}=a\left(\frac{B}{\sqrt{\mu_{0} \tau_{h_{1}} m_{\mathrm{a}}}}\right)^{-1}$ is the Alfvén transit 
time. During the reconnection we can estimate the radial thermal conductivity as being enhanced in proportion to the mean square stachastic field amplitude 25 ; such that $\kappa_{r} \sim$ $\left(\frac{B H}{B}\right)^{2} \kappa_{i, r}$. The thermal transport time can then be estimated

$$
\tau_{T}=a^{2}\left(\frac{B}{\delta B}\right)^{2} \frac{m_{c}}{3.2} T_{e} T_{e c}
$$

where $t_{e r}$ is the electron-electron collision time. We can proceed similarlv for the mean diffusiun time but now noting that mass transport will occur at the sound speed $\sim \sqrt{T_{c} / m_{z}}$. S, that the diffusion time is obtained

$$
\tau_{D}=a^{2}\left(\frac{B}{\delta B}\right)^{2} \frac{m_{i}}{T_{i} \tau_{i i}}
$$

where it has again been assumed that $T_{i}=T_{c}$. For typical plasma conditions $T_{R} \sim$ $2111 \mu s . T_{\varepsilon}=50 \mathrm{el} ; n_{\varepsilon}=5 \times 10^{19} \mathrm{~m}^{-3} \cdot B=0.3 T \cdot \frac{\delta B}{B}=0.112$, and $a=0.1 \mathrm{~m}$ the folluwing times are computed $\tau_{A}=10.1 \mu \mathrm{s}, \tau_{x}=9.6 \mu s, \tau_{T}=5.9 \mu \mathrm{s}$, and $\tau_{D}=4811 \mu \mathrm{s}$. So we spe the previonsly assiumed ordering holds $\tau_{x} \sim T_{T} \ll T_{D}$.

\section{Summary and Conclusions}

Wis have demonstrated the extrajolation of a novel measurement techniqute to higher plasma temperatures. In this way, we are able to attain estimates of the transport quantity $D_{\text {_ }}$ in the $S-1$ spheromak. Incerpretation of $C l /$ emission profiles is dependent on ionization and, therefore, accurate estimates of the local $n_{e}$ and $T_{e}$ are necessary. These were provided by Thomson scattering.

Interpretation of the emission profiles follows from direct solution of the impurity continuity equation. Speries density profiles may be directly related to emissivity profiles since. $n_{e}$ and $T_{e}$ have no strong gradients over the spatial extent of emission. Furthermore, the effects of recombination. including charge exchange, are negligible.

Over the modest range of plasma parameters investigated, we have found a Bohm-like dependence for the measured diffusion coefficient. More specifically, the relation $D_{\downarrow} \sim$ 
$5.25 \times D_{B a h m}$ represents all our data quite well. In addition, no density dependence is abserved. We have also demonstrated a correlation between $D_{\perp}$ and plasrna pressure gradients following the temporal evolution of the discharge. Finally, the enhanced transport appears to be universal, and the relaxation event 11. may not be responsible for enhanced particle transport.

\section{ACKNOWLEDGEMENTS}

This work was performed under the support of US DOE contract number \# DE-AC02. 76-C.HO-3073) 


\section{References}

11. ROSEnBluth, .W. N. and BUSSAC, M. N., Nucl. Fusion 19 (1979) 489.

(2) TAYLOR, J. B., Phys. Rev. Lett. 33 (1974) 1139.

3. T:AYlor, J. B., Relaxation of Toroidal 1)ischarges, in Pulsed High Beta Plasmas, edited bv EVANS, D. E., page 59, Pergamon Press, New York, 1976.

(4) TAYLOR, J. B., Reviews of Hodern Physics 58 (1986) 741.

(3) LEVinton, F. M. and MEYERHOFER, D. D.. Rev. Sci. Instrum. 58 (1987) 1393.

(6) MEYerhofer, D. D., LEVINTON, F. M., and YAMADA, M., Phys. Rev. Lett. 60 (1988) 933.

[7! ELLIS, Jr., R. A., JANOS, A., JOYCE, J., and YAMADA, M., in Proceedings of the Fifth Symposium on the Physics and Technology of Compact Toroids, pages 39-45, Mathematical Sciences Northwest, Bellevue Washington, 1983, 1982.

f8 YAMADA, I., ELLIS, JR., R., FLRTH, H. P., HART, G., JANOS, A., JARDIN, S., LEvinton, F., MEyerhofer, D., MiMURA, M., NAM, C. H., PAUl, S., SPERDUTI, A., VON GOELER, S., WYSOCKI, F., and YOUNG, P., Initial Results from 5 - 1 Spheromak, in Plasma Physics and Controlled Nuclear Fusion Research, 1984, volume 2, page 535, 1AEA, Vienna, 1985, London Conference.

[9] JANOS, A., Phys. Fluids 29 (1986) 3342.

IUI JARDIN, S. and CHRISTENSEN, U., Nucl. Fusion 21 (1981) 1665.

1!. ONO, Y., ELLIS, Jr., R. A., JANOS. A. C., LEVINTON, F. M., MAYO, R. M., MOTLEY, R. W, CEDA, Y., and YAMADA, M., Relaxation Phenomenon in the High Temperature $S$ - 1 Spheromak, Terhniral Keport 2520, PPPL, 1988, submitted to Phys. Rev. Lett. 
12! MAYO, R. M., LEVINTON, F. M., MEYERHOFER. D. D., PALL. S.. UEDA. Y'.. and YAMADA, M., Spatial and Temporal Behavior of Hydrogen and Carbon in the S - I Spheromak, in Proceedings of the Eighth Compact Toroud Symposium and Ninth U.S. Japan Workshop on Compact Toroids, page 69, University of Maryland, 1987.

13, LEVINTON, F. M. and NAtRATIL, G. A., Rev. Sci. Instrum. 54 (1983) 35.

14. LEVINTON, F. M., MEYERHOFER, D. D., MAYO, R. M, and YAMADA, M.. Confinement and Power Balance in the $S$ - 1 Spheromak, to be published, 1988.

15! BELL, K. L., GILBODY, H. B., HLGHES, J. G., KINGSTON, A. E., and SMITH. F. J., J. Phys. Chem. Ref. Data 12 (1983) 891.

16) HART, G. W., JANOS, A., MEYERHOFER, D. D., and YAMADA, M., Phys. Fluids $29(1986) 1994$.

17' ABRAMOWITZ, M. and STEGUN, I. A., editors, Handbook of Mathematical FuncŁzons, Dover Publications, Inc, New York, 1972.

[18] HULSE, R. A., Nucl. Tech./Fusion 3 (19R2) 259.

[19] PhANelf, R. A., JANEV, R. K., and PINDZOLA, M. S., Alomic Data for Fusion Vol. V: Collisions of Carbon and O:ygen Ions with Electrons, $\mathrm{H}, \mathrm{H}_{2}$, and $\mathrm{He}$, ORNL 6090/V5, Oak Ridge National Laboratory, 1987.

21) HART, G. W., LEVINTON, F. M., and MCNEILL, D. H., Rev. Sci. Instrum. 57 (1986) 2218 .

(21) HINTON, F, L., Collisional Transport in Plasma, in Handbook of Plasma Physics, lol. I Basic Plasma Physics, edited by GALEEV, A. A. and SUDAN, R. N., page 148, North-Holland Publishing Co., Amsterdam, 1983.

22] LYAMA, T., HONDA, Y., NAGATA, M., NISHIKAWA, M., OZAKI, A., SATOMI, N., and WATANABE, K., Nucl. Fusion 27 (1987) 799. 
23) HART, G. W., CHIN-FATT, C. DESILVA, A W., GOLDENBACM, G. C., HESS. R. and SHAW, R. S., Phys. Rev. Lett. 51 (1983) 1558.

24| FI'KTH, H. P., KILLEEN, J., and ROSENBLLTH, M. N.. Phvs. Fluids 6 (1963) 459.

25 RECHESTER, A. B. and ROSENBLUTH, M. N., Phrs. Rev Lett. 40 (1978) 38. 


\section{Figures}

Fig. 1 Schomatic of the $S-1$ device showing the carbon injection diagnostic (nat to scale). Funnel stabilizers not shown.

Fig. 2. Setup of the carbon injection experiment showing the relationship of the injection probe and coupling optics to the spheromak plasma.

Fig. 3. a) Spectral emission trace in the range of 4201 A to 4825 A for a tupical $14 k 1^{\circ}$ carbon injection plasma with background subtracted. The probe position is $R=42 \mathrm{~cm}$ and the line of sight for this channel intersects the midplane at $R=42.5 \mathrm{~cm}$. b) Spectral emission trace for the same plasma conditions with the probe removed. Notice the change of scales.

Fig. 4. Radial emission profile for $C I /$ at $4267 \mathrm{~A}$. Dashed line is a gaussian fit to the raw data with $r_{0}=-10.83 \mathrm{~cm}$.

Fig. 5. Peak of the CII (4267A) emission profile vs. time after plasma initiation. The spark probe was discharged at 250 pis (open circles). The $x$ 's are the steady-state profile peaks under the same conditions.

Fig. 6. Time evolution of $r_{1 / 2}$ for $C I I$. Open circles are the experimental half-widths for several $8 \mathrm{kl}^{\circ}$ discharges. The $\mathrm{x}$ 's and dashed line are the results of the simulation using the experimentally determined $D_{\perp}$ by the method of peak heights. The solid line represents the $r_{1 / 2}$ value found from the steady-state emission profiles.

Fig. 7. Example $C I I$ steady-state emission profiles (solid lines) overlaid by best fits to Eq. (6) (dashed lines).

Fig. 8. $n_{e}$ as a function of $T_{r}$ for all the $r=42 \mathrm{~cm}$ data showing an inverse dependence.

Fig. 9. $D$. dependence on $n_{e}$ for the smali parameter space window $T_{e}=45-65 \mathrm{eV}, B=$ $2(1)(1-250) G$. 


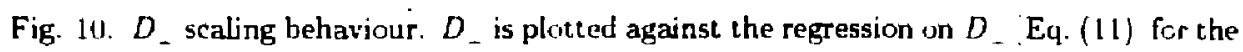
entire data set consistent with $t \leq 37 \mathrm{~J} \mu \mathrm{s}$ and $r=42 \mathrm{~cm}$. I' indicates the operational bank voltage.

Fig. 11. Half-width $r_{1 / 2} \quad r_{o} v s . T_{e}$ for $B \sim 24011\left(i, n_{e} \sim 7 \times 10^{13} \mathrm{~cm}^{-3}\right.$.

Fig. 12. The values $D_{\perp}\left(\bullet^{\prime} s\right), \overline{5} .25 \times D_{B o h m}\left(c^{\prime} s\right)$, and $D_{1 \mathrm{cl}}\left(\Delta^{\prime} s\right) v_{s} T_{e}$.

Fig. 13. Time resolved particle transport and pressure gradients in $S-1$ plasmas. a) measured $D_{\text {. }}$ vs, time for a $I^{\circ}=I I \mathrm{kV}^{\circ}$ case. b) measured $D_{1}$ vs. time for a $\mathrm{I}^{-}=14 \mathrm{kI}^{\mathrm{r}}$ rase, c) inverse pressure gradient scale length $\kappa=\frac{1}{p} \partial \vec{p}$ for a $l^{\prime}=14 \mathrm{k} \cdot \mathrm{l}^{\circ}$ case. 


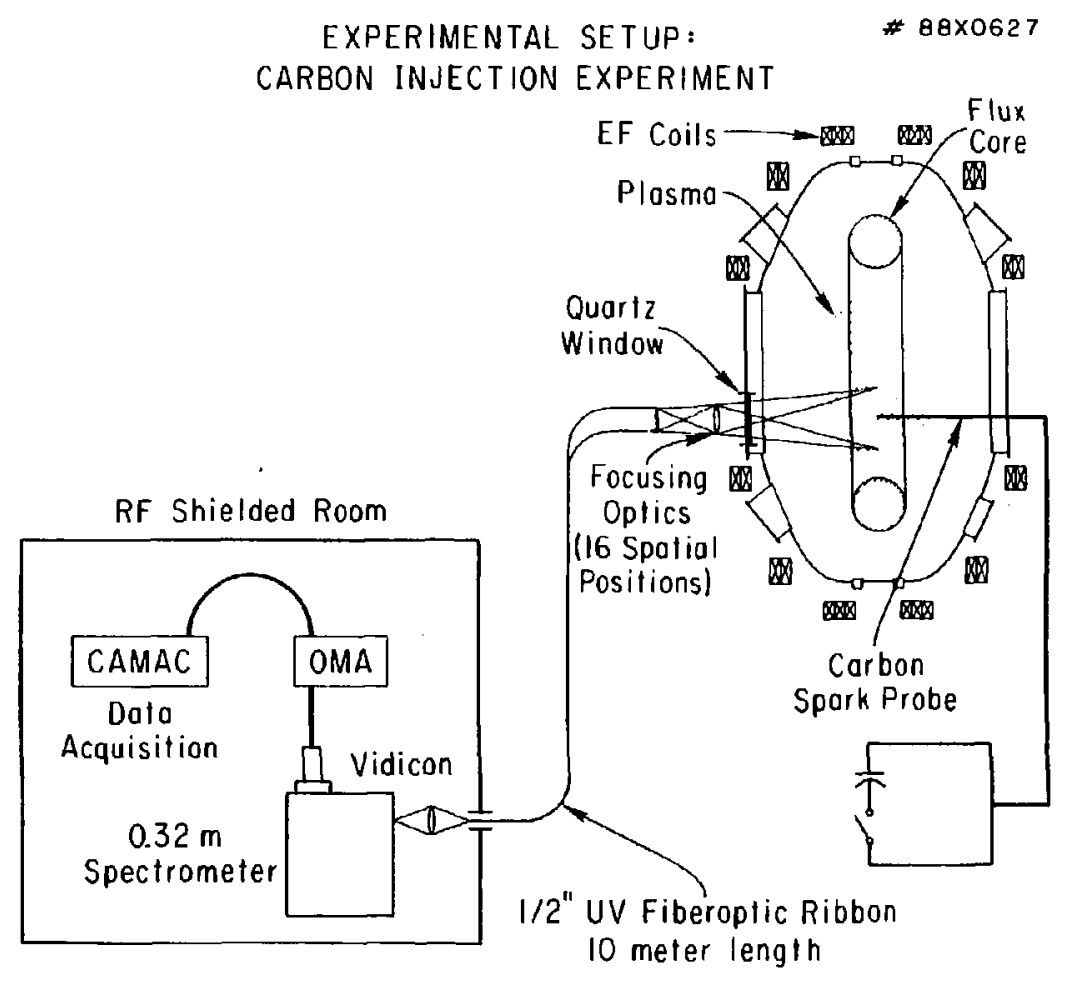

Fig. 1 
* $88 \times 0632$

DETAILED VIEW OF SPARK EXPERIMENT SETUP

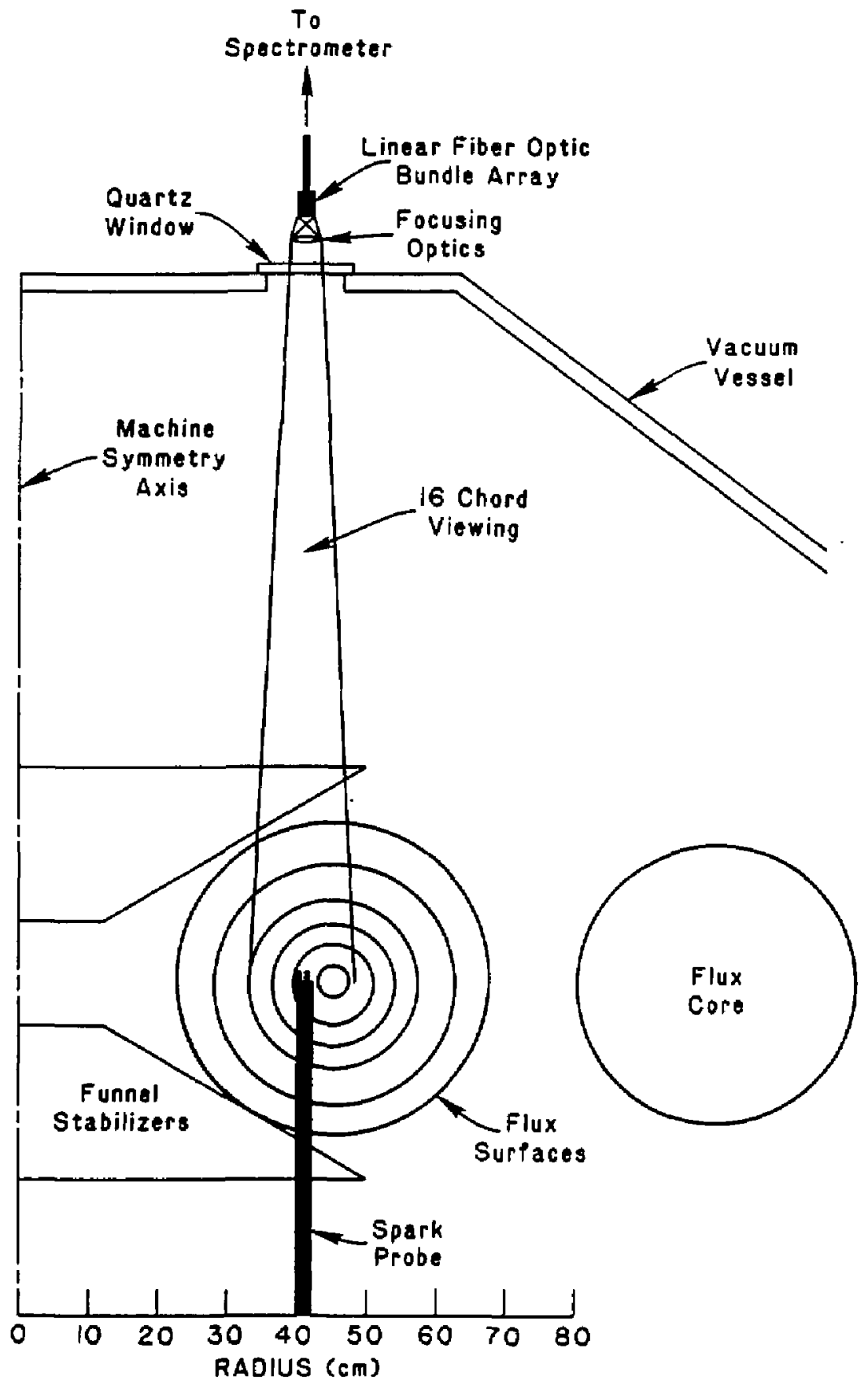

Fig. 2 


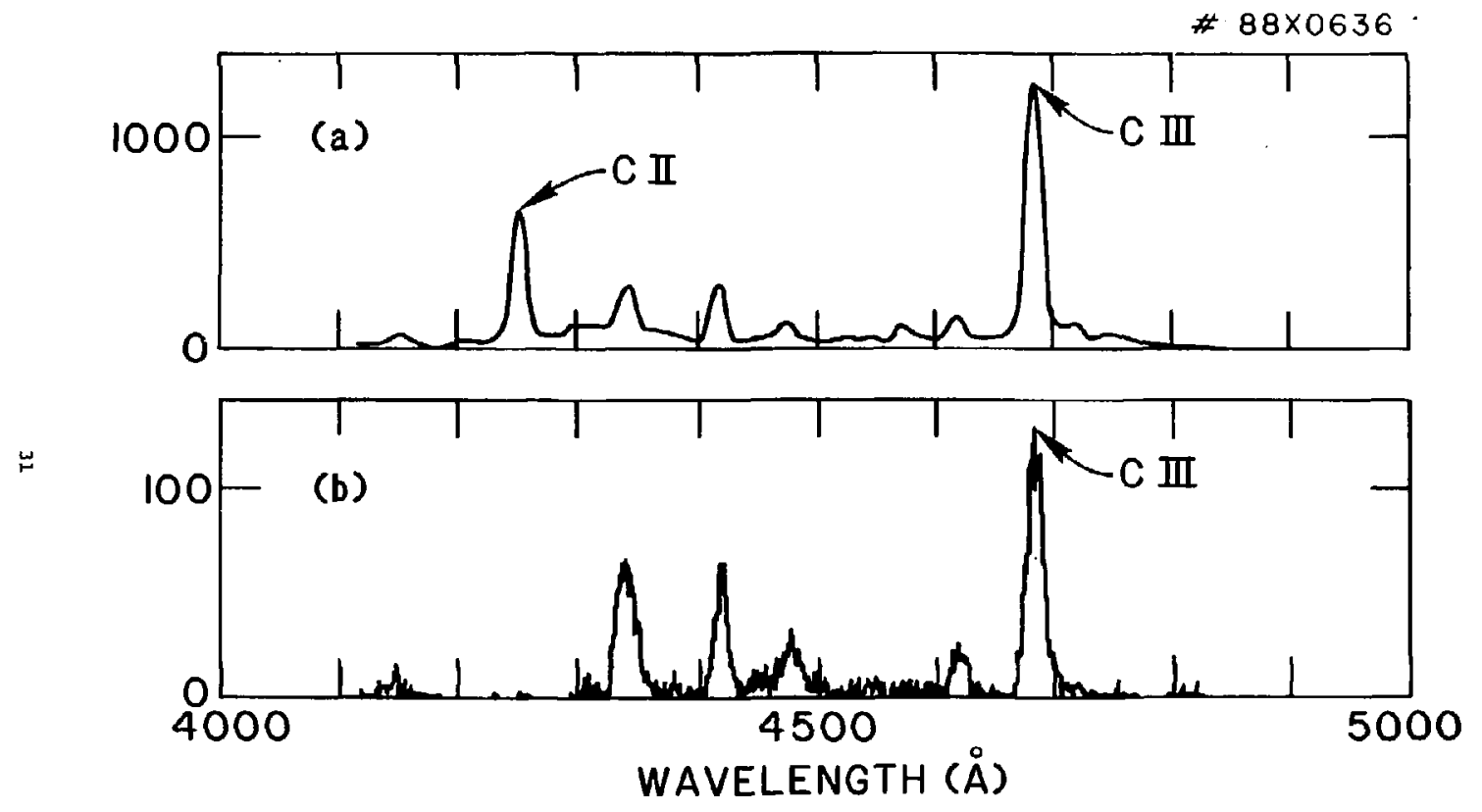


* $88 \times 0638$

w

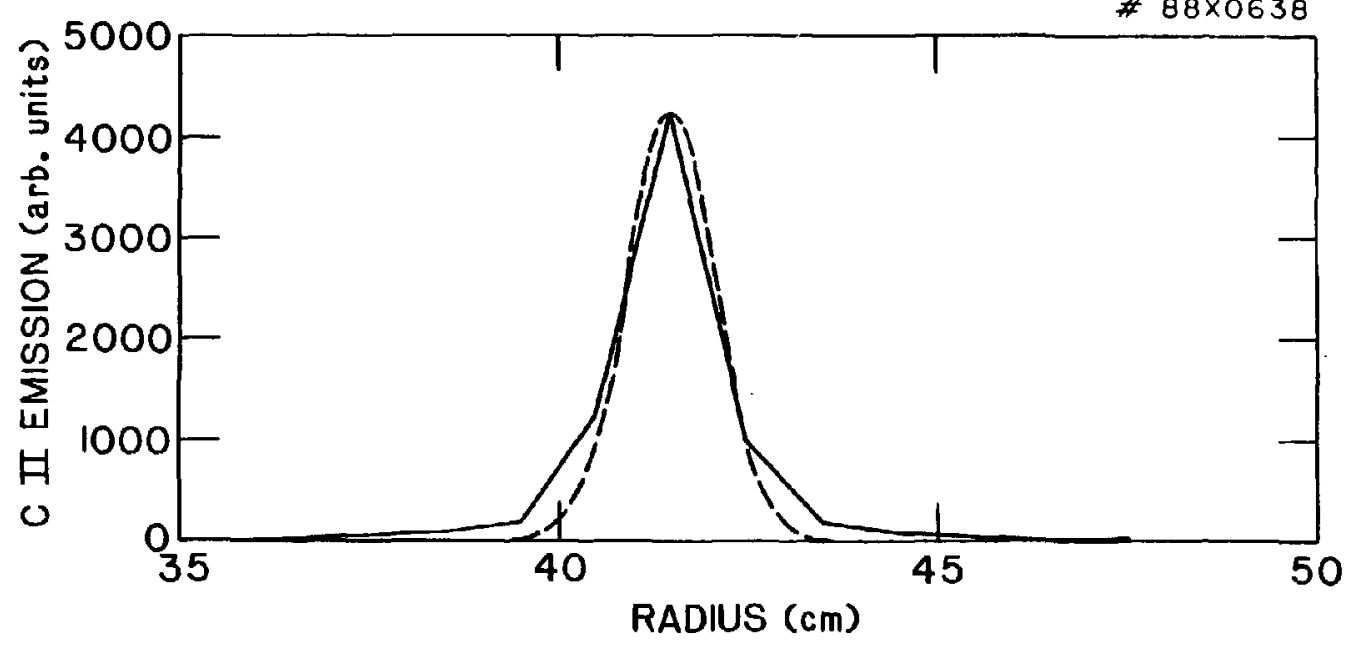




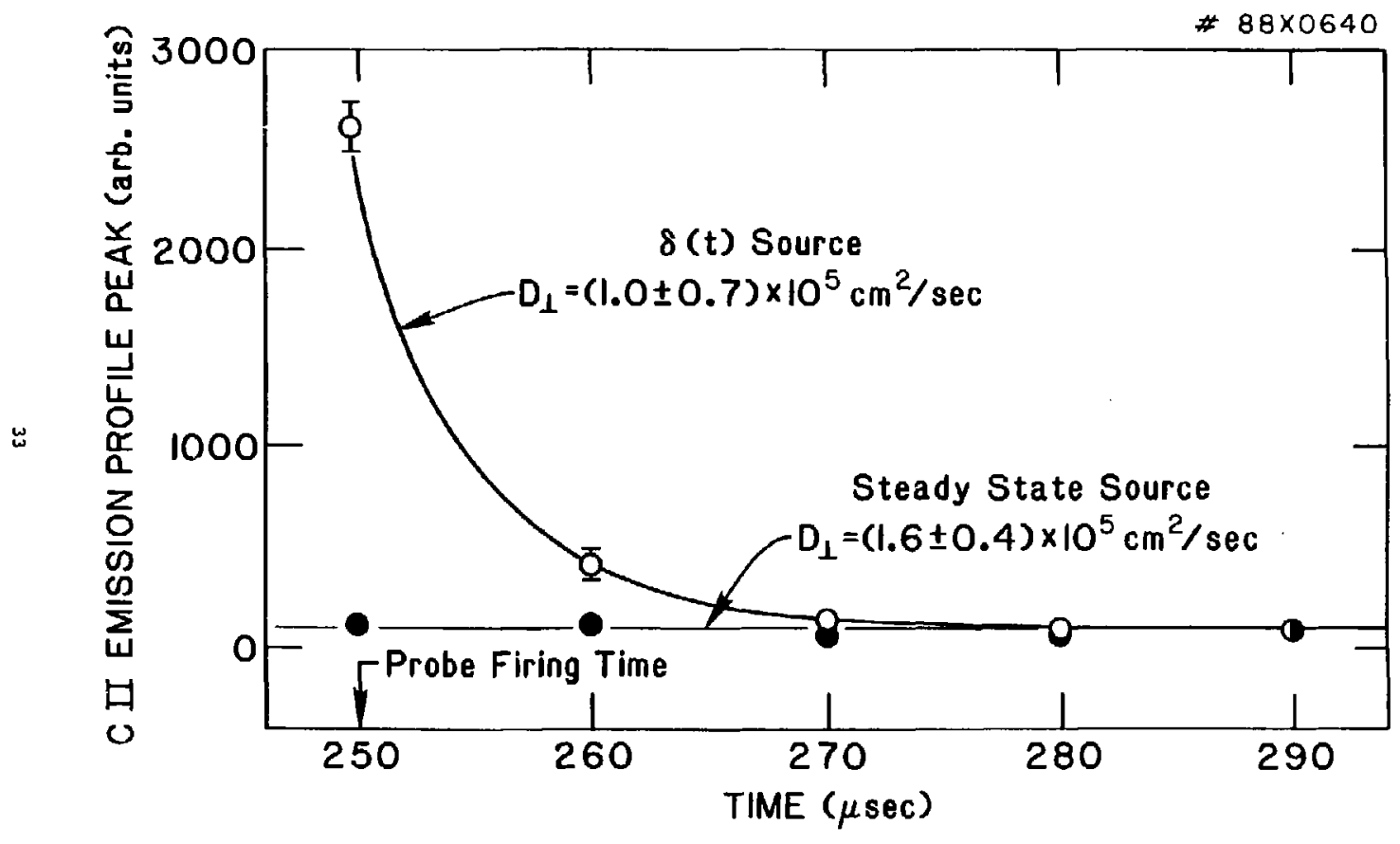




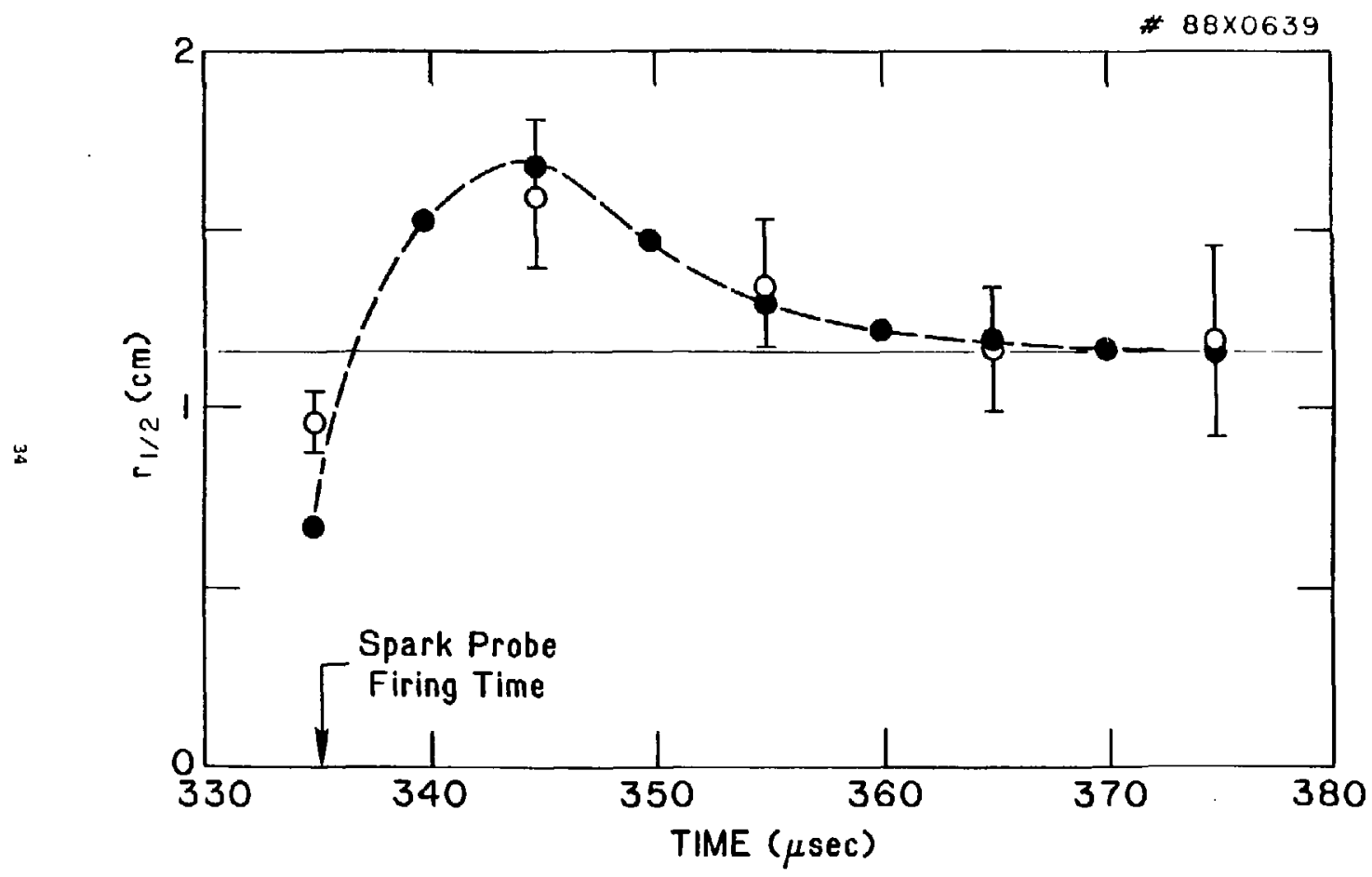

Fig. 6 

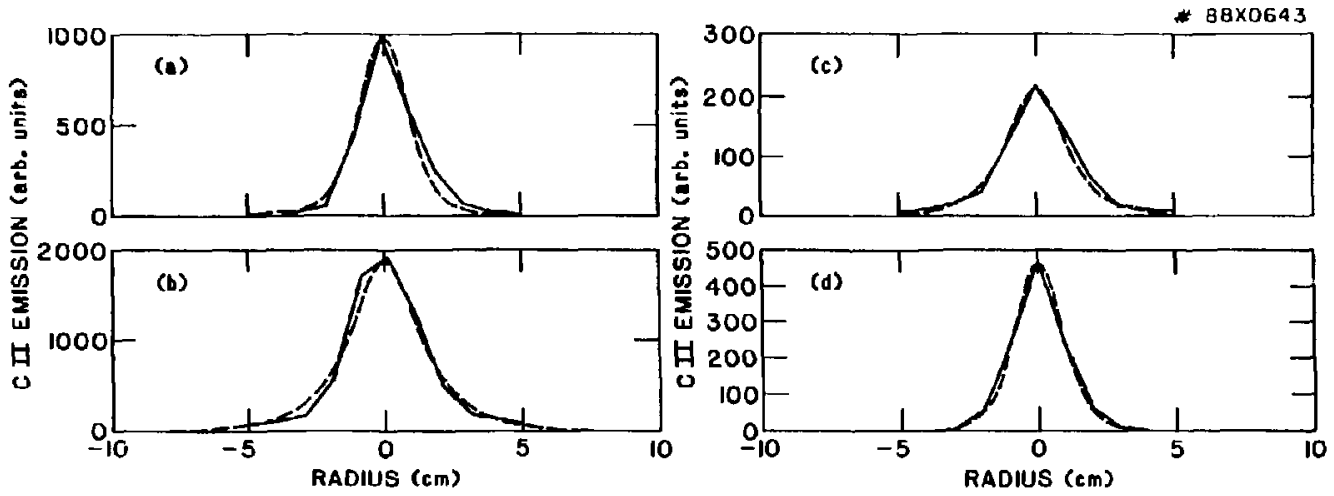


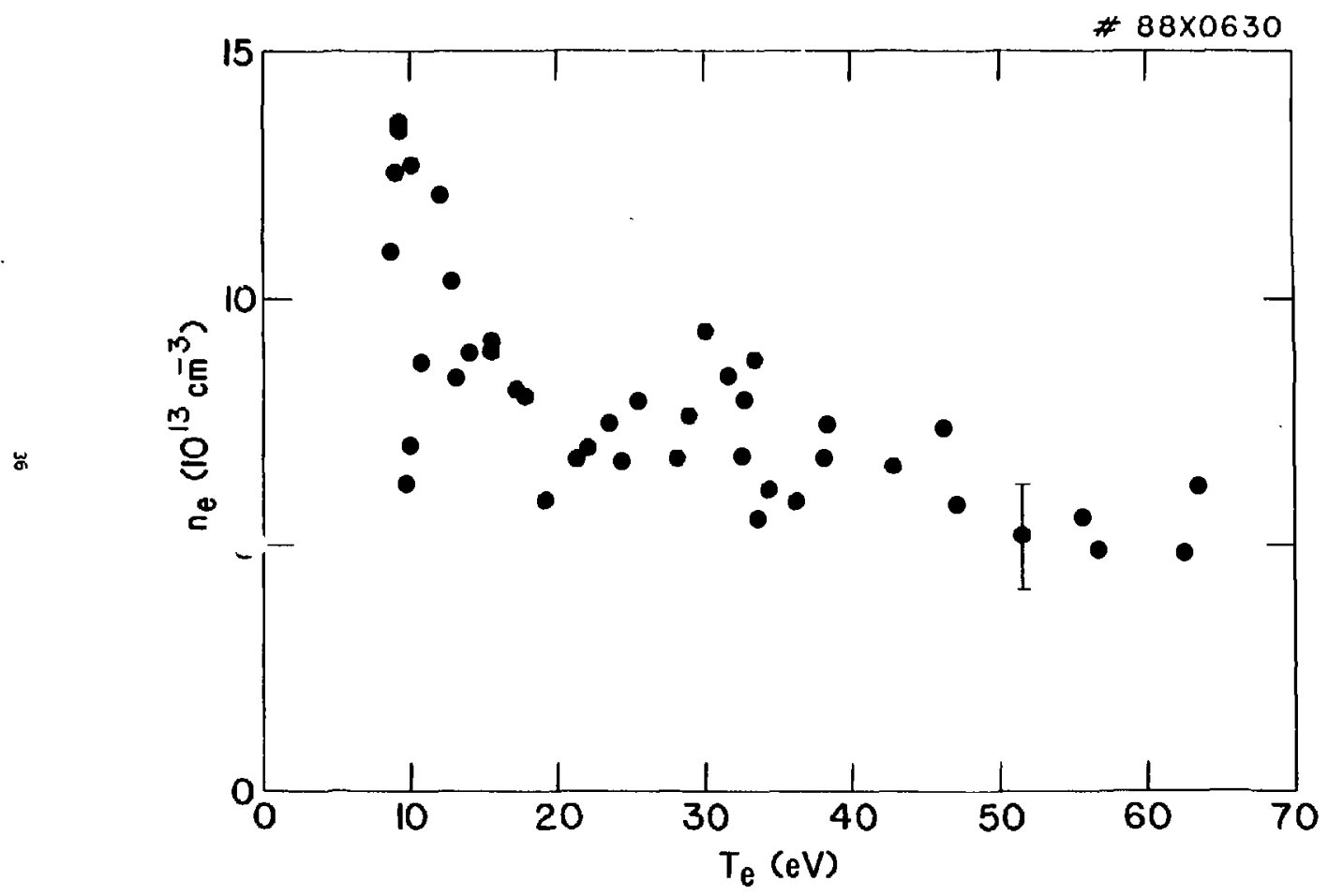

Fig. 8 


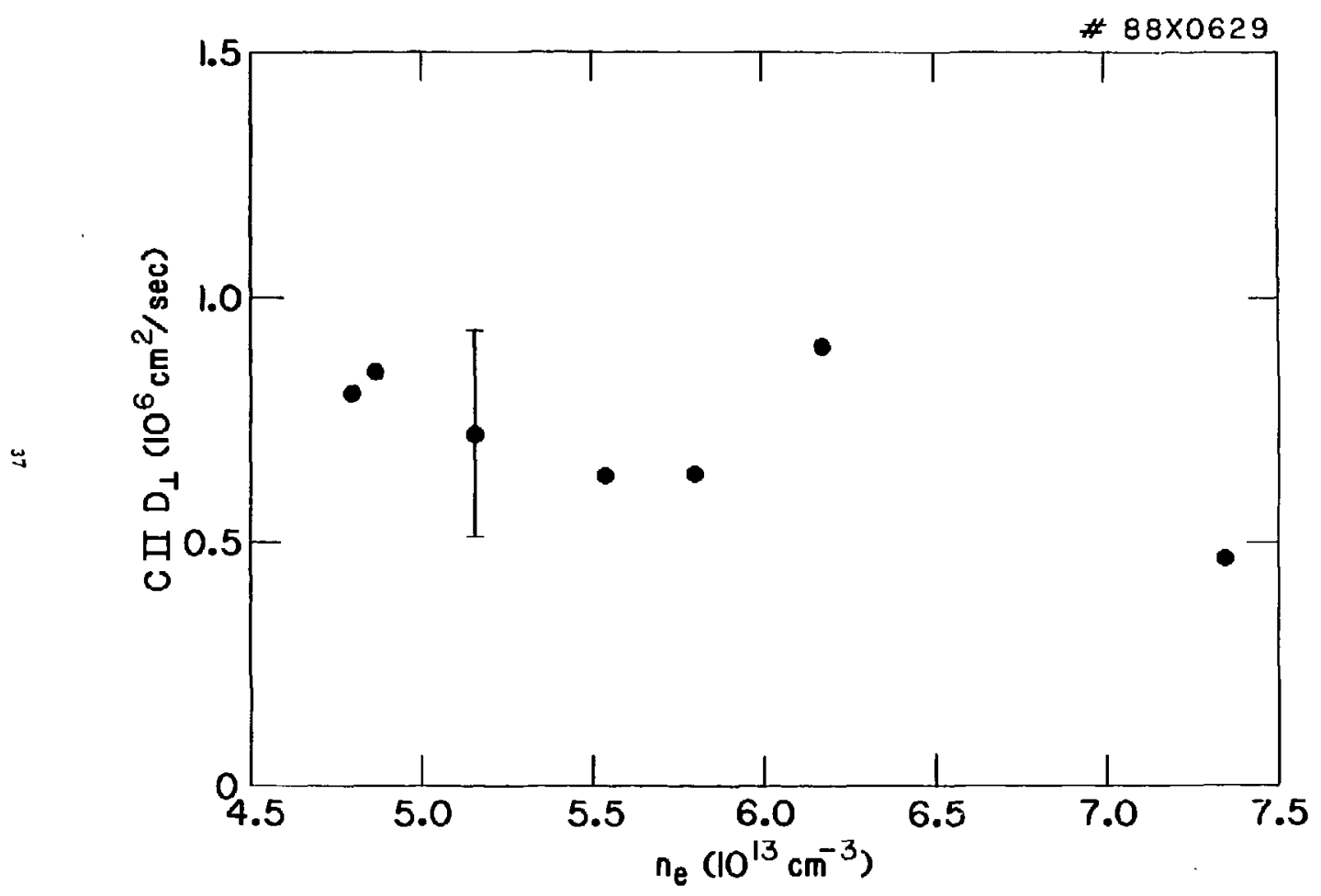

Fig. 9 


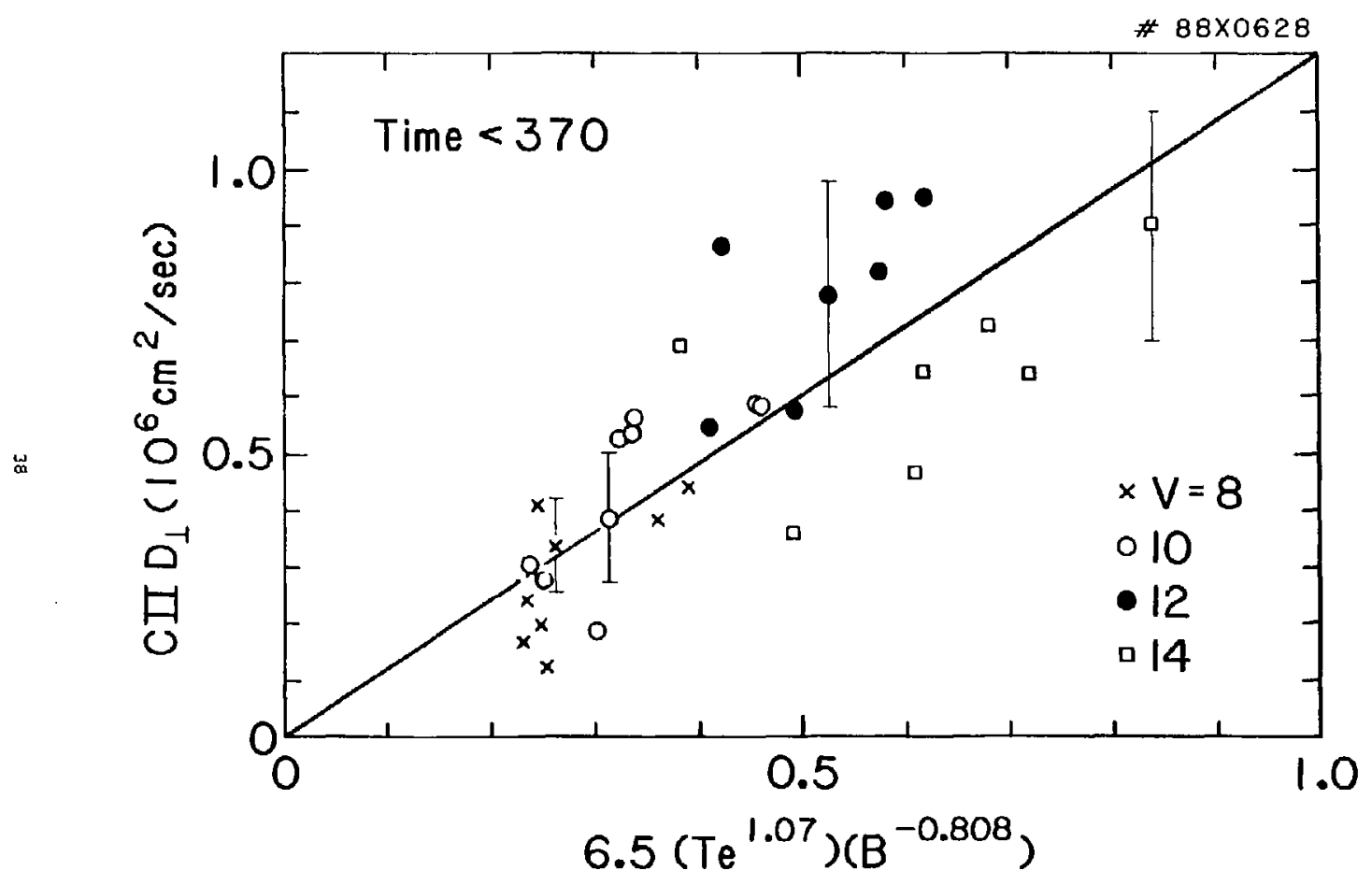

Fig. 10 
$\$ 88 \times 0812$

$\ddot{\psi}$

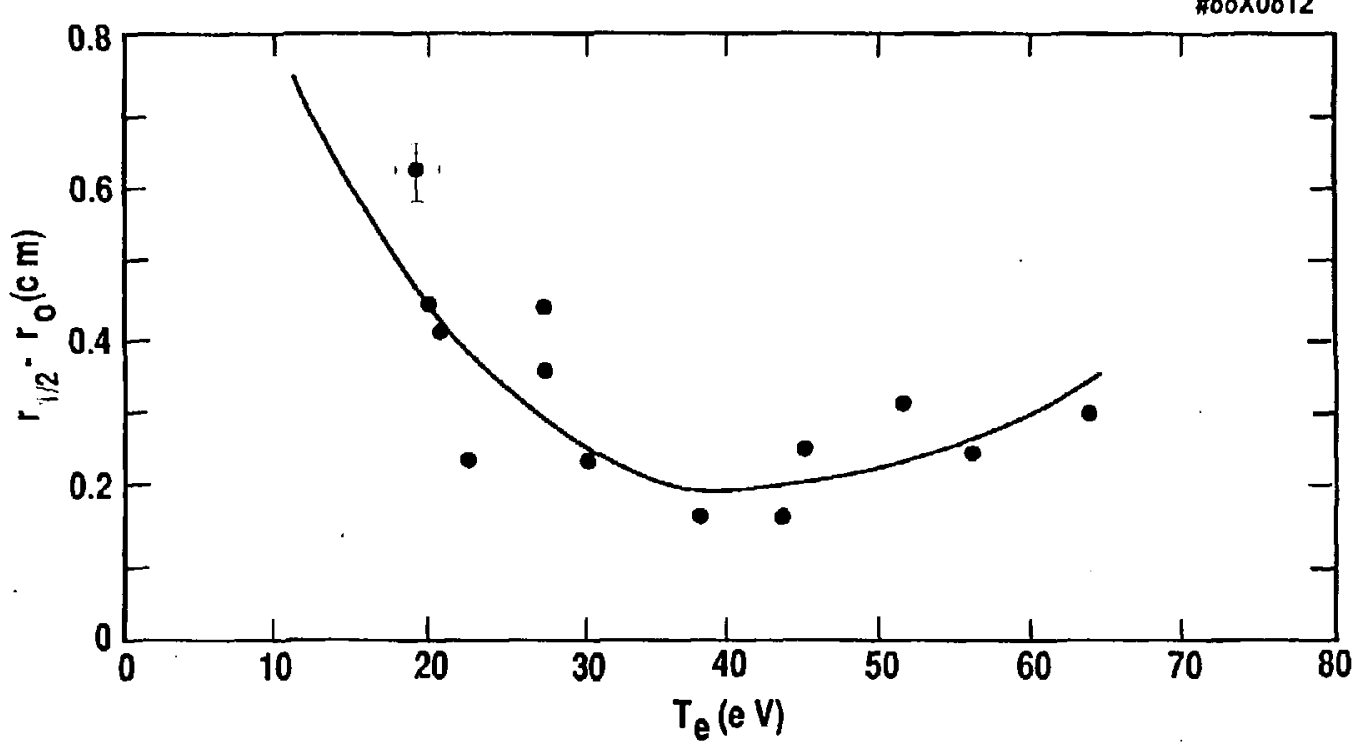

Fig. 11 


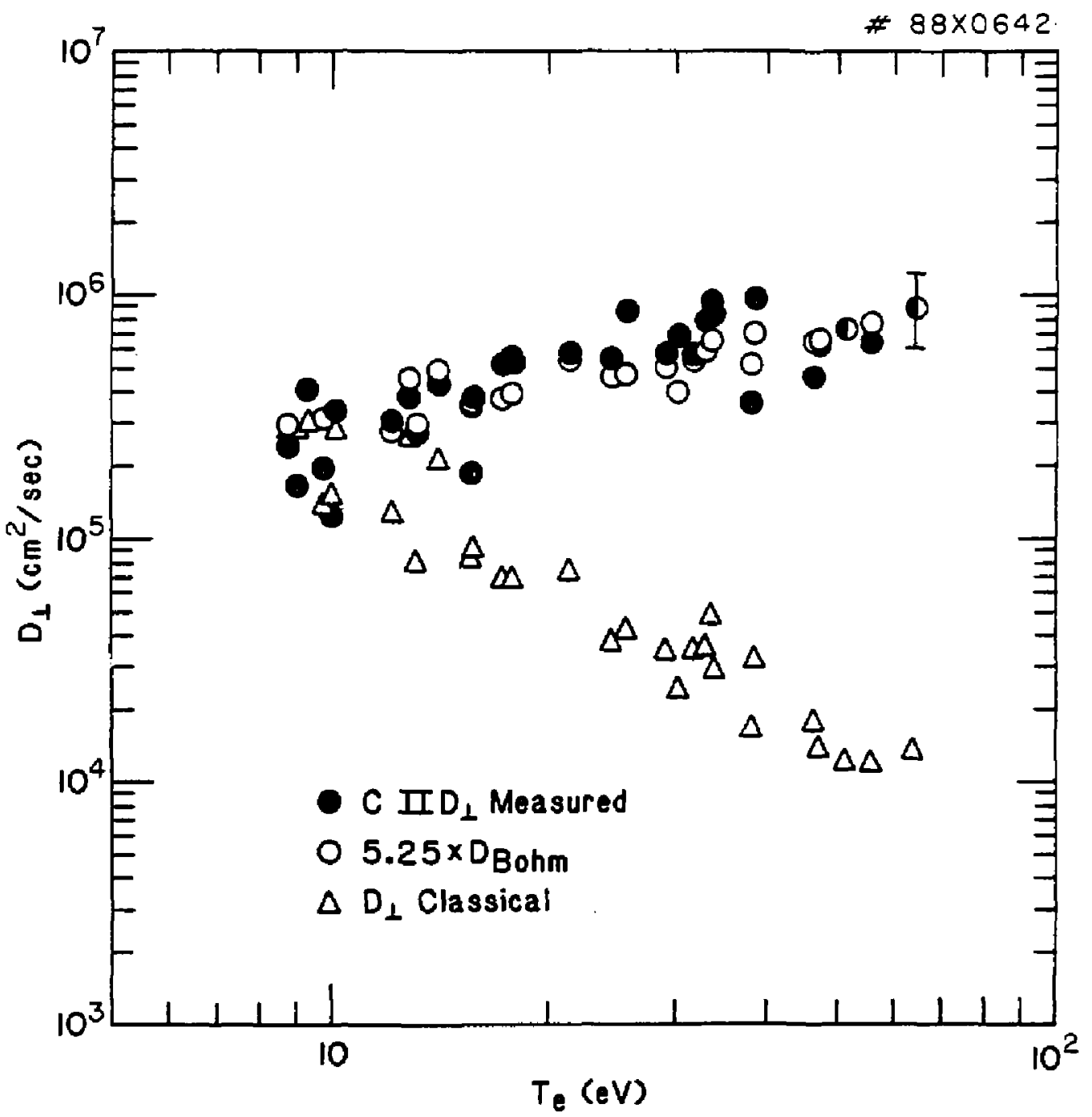

Fig. 12 


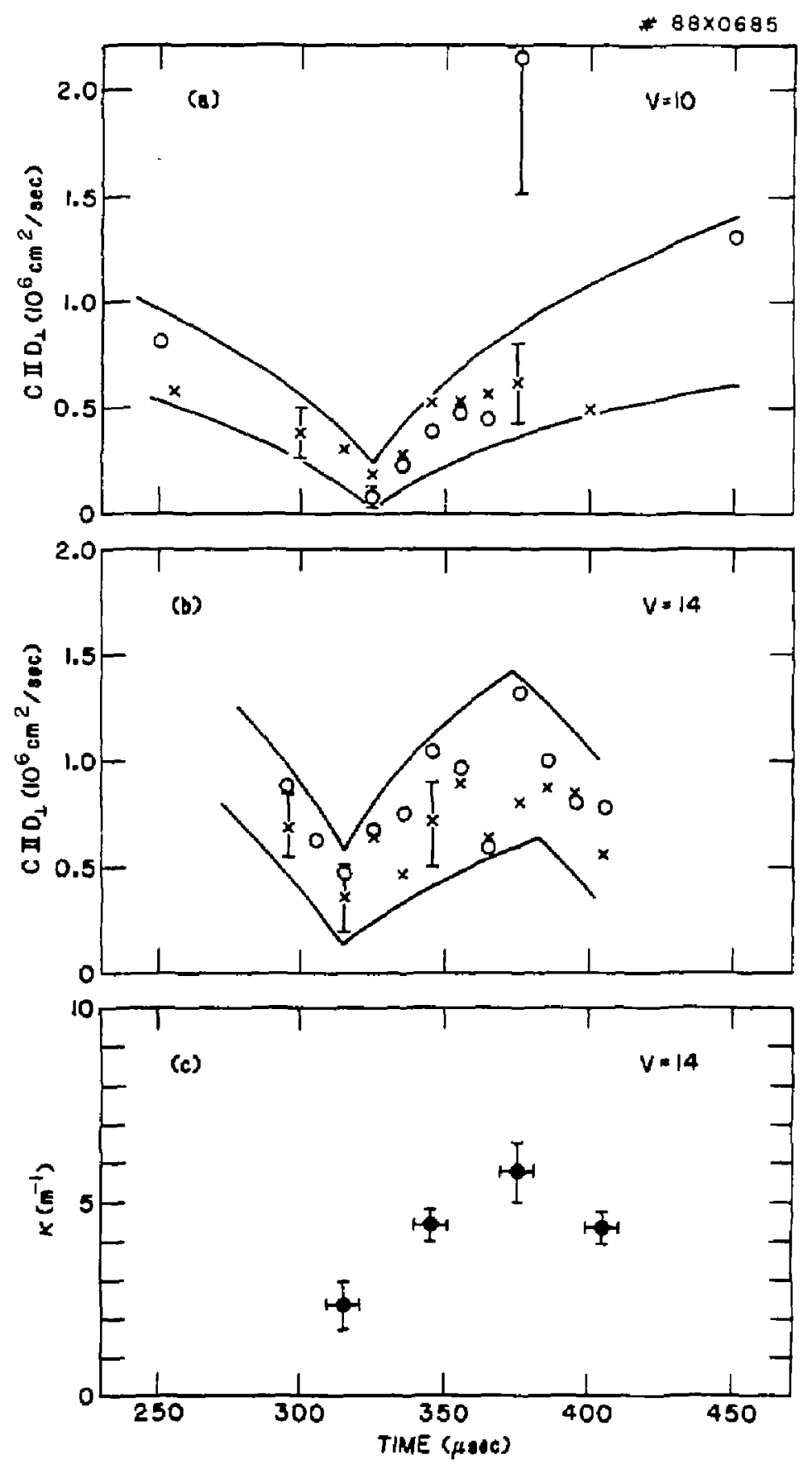

Fig. 13 
Dr. Frank J. Psolonl, Univ of Wollongong, AuSTRALIA Prof. M.H. Brannan, Univ Sydnoy, AUSTRALIA PIasma Resuerch Lab., Australian Nat. Univ.. AUSTRALiA Prof. I.R. Jones. Fi inders Univ., Australia Prot. F. Cap, Inst Theo Phys, Austria

Prof. H. Heindler, Institut f ur Theoretische Physik, AUSTRIA M. Coossens, Astroncmisch Instituut, BELGIuH Ecola Royale Militaira, Lab de Phys PIasmes, BELgIuM Comission-Eurogean, Dg-XII Fusion Prog, BELGIuM Prof. R. Boucique, Laboratoriun voor Netuurkunde, EELGIUM Dr. P.H. Sakanaka, Instituto Fisica, BRAZIL Instituto De Pesquisas Especissi-INPE, BRazIL Docunents Office, Atomic Energy of Canada Limited, CAMADA Dr. M.P. Bachynski, IP9 Technologies, Inc., CAwnoh Dr. H+M. Skarsgard, University of Saskatchevan, CANADA Dr. H. Barnard, University of British Columia, Caknoh Praf. J. Teichann, Univ, of Montreal, Cuwpa Prof. S.R. Sreanivasan, Univarsity of Calgary, Cawan Prof. Tudor W. Johnston, IMRS-Energle, CAwOA

Dr. C.R. Jaess, Univ. of Alberta, CAMnda Dr. Poter lukec, Komentkeno univ, CzEchoslowakiA

The Librarian, Culha Laboratory. ENGLAN

The Librarian, Rutharford Applaton Laboratory, ENGLAno Mrs. S.A. Hutchinson, JET Library, ENGLANo C. Mouttet, Lab. de Phrsique des Mllieux Ionisés, France j. Radat, Cen/cadarache - Bat 50s, fRAnce Univ, of Ioonnina, Library of Physics Dept. GREECE

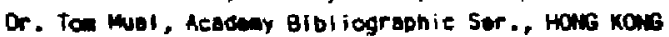
Preprint Library. Hungari on Acadeny of Sciences, Hurary Dr. B. Dasgupta, Sahe Inst of Nucl. Phys., INDiA Dr. P. Kaw, Institute for Plasing Reseerch, INOIA Dr. Philip Rosenau, Israel inst. Tech, ISRAEL Librarion, Int'I Ctr Theo Phys, ITALY Prof. G. Rostagni, Univ Di Padora, I TALY Miss Clel ia De Palo, Assoc ElRatoh-Etea, ItALY Bibliotaca, Instituto di fisica del Plasma, ITALY Dr. H. Yanito, Toshiba Ros \& Dev, JAPAY Prof. 1. Kamakani, Atonje Enorgy Res. Institute, JAPAM Prot. Kyoji Mi shikaws, Univ of Hiroshima, JAPAH Direc. Dept. Largo Tokamak Ras. JAERI, JAPAN Prof. Satoshi Itoh, Kyushu University, JAPAN Rosearch Info Center, Nagoye University, JAPMA Prof. S. Tonake, Kyoto University, JAPAN Library, Kyoto University, JAPAN Prof. Nobuyuki Inous, Uniyersity of Tokyo, JAPAN 5. Mor $i$, JAERI, JAPAN Librarian, Kores Aduanced Energy Res. Institute, KOREA Prof. 0,1. Choi, Adv. Inst Sci \& Tech, KOREA

Prof. B,S. Liley, Univarsity of halkato, NeW zeAlno institute of PIasme Physics, PEOPLE'S REPLALIC of CHIMA Librarian, Institute of Phys., PEOPLE's REPUBLIC OF CHINA Library, TsIng Hua University, PEOPLE's REPUBL IC Of CHIMA
Z. Li, Southwest Inst. Physies, PEOPLE's REPUgl IC Of CHINA Prof. J.A.C. Cabral, inst Superior Teenico, PORTuGAL Dr. Octovian Patrus, AL I CUZA University, ROMANIA Dr. Johan de Villiers, Fusion Studies, AEC, SO AFRICA Prof. M.A. Hellberg, University of Natal, SO AFRICA C.I.E.M.A.T., Fuslan DIY. Library, SPAIN Dr. Lennert Stenflo, University of UHEA, SWEDEN Library, Royal Inst Toch, SWEDEN Prof. Hans Wilhelmson. Chelnurs Univ Tech, SwEDEN Centre Phys des PI asmas, Ecole Polytech Fed, SwITZERLAND Bibliatheak, Fom-inst Voor Plasma-Fysica. THE NETHERLAkDS Dr. D.0. Ryutav, Sibarian Acad Sel, USSR

Dr. G.A. El iseer, Kurchator Instituta, USSR

Dr. V.A. Glukhikh, Inst Electrophysical Apparatus, USSR

Dr. V.T, Tolok, Inst. Phys. Tech. USSR

Dr. L.M. Kovrizhnykn, Insti tute Gen. Physics, USSR

Huclear Ros. Establishment, Julich Lta., W. GERuANY Bibliothek, Inst. Fur Plasmaforschung, G. GERANY Dr. K. Schindler, Ruhr Universitat Bochum, H. GERaAnr ASDEX finading Ra, IPPMdax-PIanck-Institut f ur

Prasmapirysik, H. GERMANY

Librarian, Maxtianck Institut, W. GEPaMAY

Prof. R.K. Janov, Inst Phys, YLeOSLAvIA 